\title{
De novo transcriptome analysis of Medicago falcata reveals novel insights about the mechanisms underlying abiotic stress- responsive pathway
}

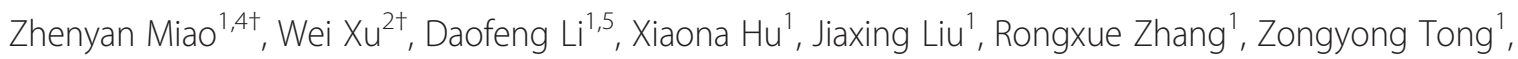
Jiangli Dong ${ }^{1}$, Zhen Su${ }^{3}$, Liwei Zhang ${ }^{3}$, Min Sun ${ }^{2}$, Wenjie $\mathrm{Li}^{2}$, Zhenglin $\mathrm{Du}^{2}$, Songnian $\mathrm{Hu}^{2^{*+}}$ and Tao Wang ${ }^{1 *+}$

\begin{abstract}
Background: The entire world is facing a deteriorating environment. Understanding the mechanisms underlying plant responses to external abiotic stresses is important for breeding stress-tolerant crops and herbages. Phytohormones play critical regulatory roles in plants in the response to external and internal cues to regulate growth and development. Medicago falcata is one of the stress-tolerant candidate leguminous species and is able to fix atmospheric nitrogen. This ability allows leguminous plants to grow in nitrogen deficient soils.

Methods: We performed Illumina sequencing of cDNA prepared from abiotic stress treated M. falcata. Sequencedreads were assembled to provide a transcriptome resource. Transcripts were annotated using BLASTsearches against the NCBI non-redundant database and gene ontology definitions were assigned. Acomparison among the three abiotic stress treated samples was carried out. The expression of transcriptswas confirmed with qRT-PCR.

Results: We present an abiotic stress-responsive M. falcata transcriptome using next-generation sequencing data from samples grown under standard, dehydration, high salinity, and cold conditions. We combined reads from all samples and de novo assembled 98,515 transcripts to build the M. falcata gene index. A comprehensive analysis of the transcriptome revealed abiotic stress-responsive mechanisms underlying the metabolism and core signalling components of major phytohormones. We identified nod factor signalling pathways during early symbiotic nodulation that are modified by abiotic stresses. Additionally, a global comparison of homology between the M. falcata and M. truncatula transcriptomes, along with five other leguminous species, revealed a high level of global sequence conservation within the family.

Conclusions: M. falcata is shown to be a model candidate for studying abiotic stress-responsive mechanisms in legumes. This global gene expression analysis provides new insights into the biochemical and molecular mechanisms involved in the acclimation to abiotic stresses. Our data provides many gene candidates that might be used for herbage and crop breeding. Additionally, FalcataBase (http://bioinformatics.cau.edu.cn/falcata/) was built for storing these data.
\end{abstract}

Keywords: Medicago falcata, Transcriptome, Legume, Phytohormones, Nodule

\footnotetext{
* Correspondence: husn@big.ac.cn; wangt@cau.edu.cn

${ }^{\dagger}$ Equal contributors

${ }^{2}$ CAS Key Laboratory of Genome Sciences and Information, Beijing Institute

of Genomics, Chinese Academy of Sciences, Beijing 100029, China

'State Key Laboratory of Agrobiotechnology, College of Biological Sciences,

China Agricultural University, Beijing 100193, China

Full list of author information is available at the end of the article
} 


\section{Background}

Abiotic stresses such as low temperature, high salinity, and drought adversely affect plant growth and productivity worldwide. The entire world is facing an increasing food requirement as the population grows continuously while crop and herbage productivity diminishes due to the deteriorating environment. Therefore, our understanding of the mechanisms underlying plant responses to external abiotic stresses is very important for breeding stresstolerant crops and herbages, as well as sustaining the agricultural industry [1].

A variety of adaptive strategies to cope with abiotic stresses have evolved in plants. These include morphological, physiological, biochemical, and molecular responses [1-5]. Hundreds of plant genes are differentially regulated in response to abiotic stresses, as demonstrated by RNA-seq analyses. The complex network of regulatory genes necessary to sense and respond to abiotic stresses has been addressed. Regulatory component identified so far include transcription factors (TFs), plant hormones, noncoding RNAs, protein modifiers and epigenetic modifications [6-9].

The growth and development of all plants is determined by the interactions between their genome and growing environment. A multitude of complex signalling systems have evolved in plants to respond to external and internal cues to regulate growth and development under abiotic stresses. Phytohormones play critical regulatory roles in these processes. Generally, phytohormones control various developmental events throughout the plant life cycle, such as patterning, cell identity, and differentiation, as well as the coordinated growth of various reproductive organs [10]. In recent years, the metabolism and core signalling components of major phytohormones, such as abscisic acid (ABA), ethylene, jasmonic acid (JA), auxins, and gibberellins (GA), have been revealed [11]. In plants, the response to abiotic stresses is through the modulation of gene expression by phytohormone-mediated signalling processes. As summarised in recent reviews, ABA remains the best-studied hormone for plant stress responses [12-16]. However, other hormones, such as ethylene, JA, GA, and auxins, are being studied to a limited extent for abiotic stress responses [17-20].

Medicago falcata, which is closely related to alfalfa (Medicago sativa), is an economically and ecologically important legume herbage and is widely distributed throughout the world. M. falcata is especially attractive because it can be grown in adverse environment regions, such as infertile and sandy soils, and is, thus more tolerant against drought and cold compared with alfalfa [21, 22]. The combination of these traits makes M. falcata one of the best stress-tolerant candidate plant species. M. falcata also consists of numerous different genotypes, each of which has diverse growth and agricultural characteristics, indicating its agricultural importance [23]. A variety of genes were reported involved in tolerant mechanism of M. falcata. Expression of multiple genes encoding myo-inositol phosphate synthase (MIPS), galactinol synthase (GolS), early light induced protein (ELIP), hybrid proline rich protein (HyPRP), S-adenosylmethionine synthetase (SAMS), and a myo-inositol transporter-like (INTlike) in response to low temperature is also associated with cold tolerance in $\mathrm{M}$. falcata plants [24-28]. Temperature-induced lipocalin (TILs) have initially been detected as massively increased proteins in response to low temperatures. Arabidopsis TIL1 is localized in the plasma membrane and its temperature response suggested a function in membrane stabilization during freezing stress [29]. A partial-length cDNA clone encoding a TIL has been obtained in M. falcata responsive to cold [30], implying its potential role in cold tolerance of M. falcata. As a legume species, M. falcata has the ability to fix atmospheric nitrogen through the establishment of a symbiotic association with bacteria called rhizobia, and this ability allows leguminous plants to grow in soils that are deficient in nitrogen, decreasing both the need for costly nitrogen fertilisers and the water pollution they may cause [31]. An organ, the root nodule, is formed to house this symbiosis. Within this organ, there is an exchange of nutrients: the bacteria provide the plant with ammonia, and the plant provides the bacteria with carbohydrates. Over the past several years, hundreds of plant and bacterial genes displaying differential expression during the nodulation process have been identified by transcriptome analyses in Medicago truncatula and Sinorhizobium meliloti [32-40], and many factors have been shown to control the nodulation process [41]. Studies of bacterial and plant mutants have led to the identification of plant genes involved in the early stages of symbiotic nodulation [42]. However, a transcriptomic analysis of nodulation signalling pathway gene expression in response to abiotic stresses is lacking in the literature.

The emergence of next-generation sequencing (NGS) technologies has allowed further study of species in which the genome sequence is available or previously unexplored species in re-sequencing and de novo sequencing aspects [43]. The technology, which allows the sequencing of the entire transcriptome (RNA-Seq), could provide expression profiles of either coding or noncoding RNAs, making important contributions to genome annotation [44, 45]. Transcriptome sequencing has become more and more popular in many research areas, especially for model species such as Arabidopsis [46], Cotton [47], Soybean [48], M. tuncatula [38, 39, 49-51] and non-model species, such as alfalfa [52-55], lentil [56], pea [57], pigeon pea [58] and cucurbits [59]. Although often used in species with a sequenced genome and high-quality gene predictions, the rapid development of software tools has allowed researchers to 
undertake the de novo assembly of a transcriptome based on only short sequence fragments, which has been widely applied in many plants [52, 60-63].

In this work, we present the expression profiles of $M$. falcata in plants grown under dehydration, high salinity, and cold conditions. We also explore evidence for novel abiotic stress-induced phytohormone metabolism and nodulation signalling. This is the first high-throughput transcriptomic study in stress-tolerant legume herbage, and we hope that it will be a valuable resource for breeding crops and herbages with enhanced abiotic stressresistance abilities in legumes or other species.

\section{Results}

Evaluation of cold, dehydration and salt stresses response of three Medicago genotypes

In order to assess the resistance ability of M. falcata (PI502449), we test Medicago truncatula ecotypes A17 and R108 under different abiotic stresses, including cold, drought and salt stresses. The methods referred to Medicago Handbook [64] and was modified. Firstly, in the cold stress test, we find that the differences in mortalities (\%) and root to aerial part ratios between M. falcata and M. truncatula are significant. After the treatment under $-6{ }^{\circ} \mathrm{C}$ for $10 \mathrm{~h}$, the mortality of PI502449 is $80 \%$, whereas the mortalities of A17 and R108 are both $100 \%$. Under $-6{ }^{\circ} \mathrm{C}$ for $6 \mathrm{~h}$, the mortalities of PI502449, A17, and R108 are $0 \%, 85 \%$, and $100 \%$, respectively. Under $-6{ }^{\circ} \mathrm{C}$ for $8 \mathrm{~h}$, the mortalities of PI502449 is $20 \%$, the other two are $100 \%$ (results are shown in Additional file 1D). Since the cold stress can inhibit the growth of roots, therefore, the root to aerial ratio, which is defined as the ratio between fresh weights of root to that of aerial part, can characterize the ability of alfalfa's resistance to cold stress. The results show that, as the cold stress time becomes longer, the root of PI502449 can still grow in compare to that of R108 and A17 (Additional file 1A). Therefore, it is obvious that the PI502449 processes a stronger ability to resist the cold stress. Secondly, drought stress is applied 7 days (control), 10 days, 12 days and 14 days, respectively, followed by re-hydration, three replicates. Fresh weight and ratio of root to aerial part were measured. The results showed that the roots of PI502449 have relative higher water contents. PI502449 has the highest ratio of root to aerial part among R108, A17, and PI502449. To sum up, the M. falcata PI502449 has the strongest ability to resist drought. In the salt stress test, we treated the soil with $0 \mathrm{mM}$ (Control), $100 \mathrm{mM}$, $150 \mathrm{mM}$ and $200 \mathrm{mM} \mathrm{NaCl}$, and then collect the content of soluble carbohydrate using a phenol-sulfuric acid method. The contents of soluble carbohydrate can be used as criteria for salt stress resistance, because the carbohydrate will increase under the salt stress to reduce the damage of $\mathrm{NaCl}$ to plantlet. Based on the results, we can conclude that A17 has the strongest ability to resist the salt stress, PI502449 the weakest (Additional file 1C). These results suggested that $\mathrm{M}$. falcata PI502449 is more tolerant against drought and cold stresses compared with $M$. truncatula. Based on these results, we attend to reveal mechanisms involved in $M$. falcata response to abiotic stresses by using RNA-seq technology.

\section{RNA-seq using the Illumina platform and the de novo assembly of the transcriptome}

In order to find out the early response genes of PI502449 under abiotic stresses, we analyzed the electrolyte leakage after the rapid stresses (Additional file 2). We picked the optimal stress treatment under which electrolyte leakage increased 2-fold or more compared with standard conditions for RNA-Seq. Plant materials were collected under dehydration (dehydrated for $2 \mathrm{~h}$ ), high salinity $(1 \mathrm{M} \mathrm{NaCl}$ for $2 \mathrm{~h})$, or cold $\left(0{ }^{\circ} \mathrm{C}\right.$ for $8 \mathrm{~h}$ ) treatment and then RNA were extracted. We developed complementary DNA (cDNA) libraries derived from $\mathrm{M}$. falcata PI502449 grown under abiotic stress and standard conditions: dehydration stress plantlets (DS), high salinity stress plantlets (SS), cold stress plantlets (CS), and standard conditions (SC). Two libraries were constructed for one sample respectively, resulting in a total of eight cDNA libraries for the RNA-Seq analysis. A total of 33,432,584,900 nt of raw sequencing data were generated from the eight cDNA libraries. After a stringent quality filtration of the raw read data using the FASTX-toolkit (http://hannonlab.cshl.edu/fastx_toolkit/ index.html), a total of 31,591,337,787 nt filtered data were selected for further analysis (Additional file 3).

To obtain a better assembly result, two assembly methods (single k-mer method and multiple k-mer method) were used for the de novo assembly of our sequencing data. The parameters used for the two methods are described in the Methods section. The de novo assembled transcripts were combined with 98,515 unique sequences (Additional file 4). The total base count of the assembly sequences was $84,416,200 \mathrm{nt}$, with the unique sequence lengths ranging from 200 to $14,802 \mathrm{nt}$. In order to explicitly evaluate the quality of the transcripts generated by assembly, we download 913 mRNAs already characterized in M. falcata from NCBI EST database. BLASTn comparisons were performed between assembly sequences and EST dataset. Total 869 (95.2\%) mRNAs had significant hits to assembly sequences. Putative functions for the assembly sequences were assigned using BLASTX searches against the nonredundant (nr) NCBI database, UniProt database, and M. truncatula proteome (for details, see the "Methods"; annotation files available at http://bioinformatics.cau. 
edu.cn/falcata). Putative functions were assigned for $50 \%$ of the sequences. We also assigned gene ontology (GO) and Kyoto Encyclopedia of Genes and Genomes (KEGG) functional classes. Annotations for genes and pathways analysed in greater detail throughout this paper were manually curated to ensure accurate analysis and interpretation. In addition, we have pursued systemic co-expression/network analysis with our RNA-seq dataset using WGCNA software [65] and we integrated the results into FalcataBase (http://bioinformatics.cau. edu.cn/falcata/network/). Users can explore the players that contribute to cold, salt and dehydration response conveniently.

The transcript profiles of M. falcata under dehydration, high salinity, and cold stresses were measured. We analysed the reads per kilobase per million reads (RPKM)normalised gene expression counts for each sequence from eight samples. Previous studies have suggested that the expression of transcripts with low RPKM scores may be statistical artefacts $[66,67]$. RPKM value depends by definition on the depth of the library. There are 20 million reads for a library on average. The mean read length is 100 nt. Based on the depth of our sequencing libraries, the results indicated that a RPKM of 2 reflects a 4-fold coverage of the sequence (coverage $=$ $2 R P K M \times 20$ million $\times 100 n t / 1000 b p$ ), assuming an equal distribution of reads across the sequence. Sequences with $\mathrm{RPKM}<2$ exhibited a low transcript abundance under the conditions tested and may not provide reliable expression data. Of the 98,515 sequences assembled, 52,725 had $R P K M \geq 2$ in at least one sample and were considered transcriptionally active. A total of 6,158 transcripts were differentially expressed (2-fold change, P-value $\leq 0.05$, RPKM $\geq 2$ ) in response to at least one stress. Heatmap display of expression profile was shown in Fig. 1c. Overlapped transcripts between increased and decreased was also checked by Venn diagram analysis and shown in Fig. 1a and $\mathrm{b}$.

We identified putative housekeeping genes that displayed little variation in expression but were expressed at relatively high levels (Additional file 5). To identify housekeeping genes, we first selected genes with an average RPKM-normalised transcript count greater than 10 . We next selected the top $10 \%$ of genes (938) with the lowest coefficient of variation (SD/mean) [48]. Finally, we picked up 587 single copy genes with the length more than $1000 \mathrm{nt}$. These housekeeping genes may be useful as reference genes in quantitative real-time PCR (qRT-PCR) or other experiments to normalise gene expression levels across different conditions [68].

Posttranscriptional regulation by microRNAs (miRNAs) is an important response to nutritional, biotic, and abiotic stresses $[69,70]$. The sequencing of miRNAs requires special library construction. Therefore, the identification of mature miRNAs is beyond the scope of this study. However, transcripts regulated by miRNAs should contain

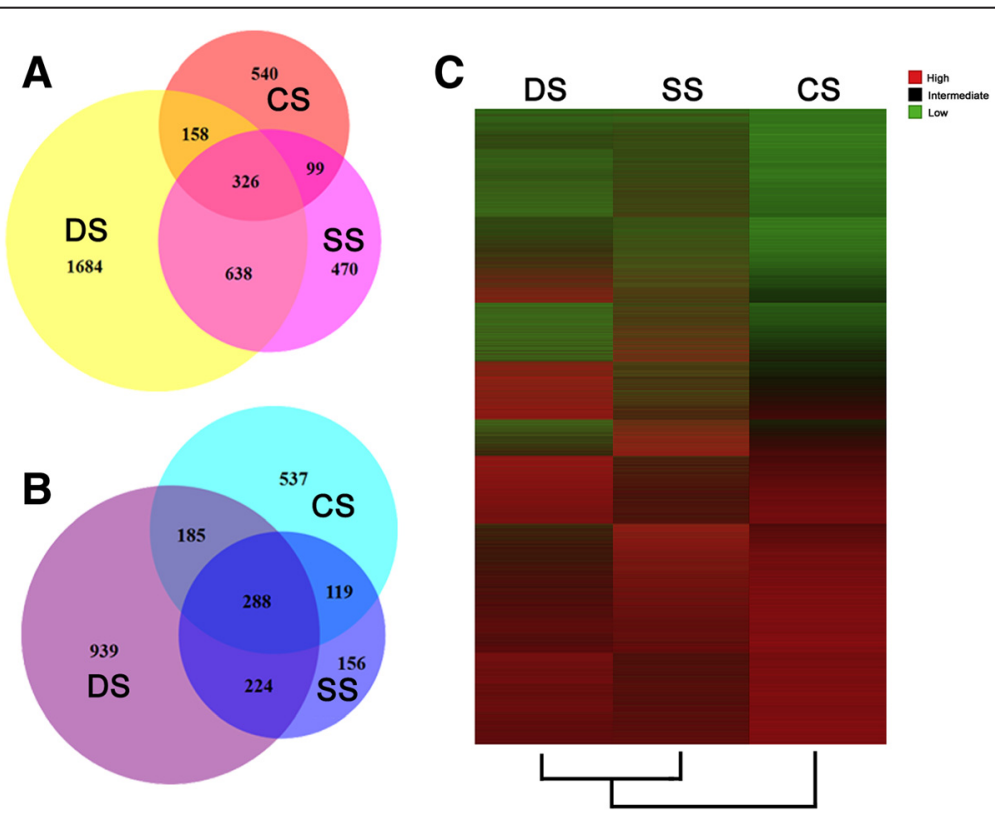

Fig. 1 Transcripts differentially expressed due to abiotic stresses. A total of 6,158 transcripts were identified as differentially expressed in the DS, $\mathrm{CS}$, and SS samples. To be considered differentially expressed, the transcript must have RPKM $\geq 2$ in at least one library, a 2-fold or greater change between the stressed and standard condition, and P-value $\leq 0.05$. a A total of 3,915 transcripts were up-regulated. b A total of 2,448 transcripts were down-regulated. $\mathbf{c}$ Heat map of the expression profiles of 6,158 transcripts differentially expressed due to abiotic stresses. Expression, represented by Z scores, is shown for transcripts differentially expressed due to three abiotic stresses. Red indicates high expression, black indicates intermediate expression, and green indicates low expression 
sequences with almost perfect complementarity to known miRNAs. We used the psRNATarget programme [71] to screen the transcripts we identified as differentially expressed due to abiotic stresses for sequences potentially regulated by miRNAs using mature miRNAs from miRBase as queries. We identified 1,132 transcripts potentially regulated by 818 miRNAs (Additional file 6). Two of the 818 miRNAs identified in this analysis (miR166 and miR399) have been previously shown to directly regulate cold and salt responses [72]. Additionally, researchers have identified a number of miRNAs that are regulated by abiotic stresses [73-75]. Several of these miRNAs were also identified in this analysis.

\section{Differential expression of transcripts due to abiotic stresses}

A total of 6,158 transcripts were differentially expressed in response to abiotic stresses: 4,460 genes in DS versus SC comparison, 2,356 genes in SS versus SC comparison, and 2,293 genes in CS versus SC comparison (Fig. 1; Additional file 7). Of the 4,442 differentially expressed transcripts identified in DS, 2,806 transcripts were upregulated, whereas 1,636 were down-regulated. Of the 2,320 differentially expressed transcripts identified in SS, 1,533 transcripts were up-regulated, whereas 787 were down-regulated. Of the 2,252 differentially expressed transcripts identified in CS, 1,123 transcripts were upregulated, whereas 1,129 were down-regulated. Additionally, 362 transcripts were induced and 288 transcripts were inhibited by all three stresses concurrently.

In response to abiotic stresses, the $M$. falcata transcriptome alters the expression of transcripts encoding for transcription factors (TFs). Of the 6,158 transcripts differentially expressed in response to all three abiotic stresses, 745 were identified as TFs (Table 1; Additional file 8). These transcripts belong to $65 \mathrm{TF}$ families. The NAC and MYB-related TF families were the two largest families responding to the abiotic stresses identified in M. falcata. We identified 62 members of the NAC TF family exhibiting increased expression in DS, 33 members exhibiting increased expression in SS, and 12 members exhibiting increased expression in CS. The number of transcripts induced by cold stress was the smallest of the three stresses.

As noted in previous studies, abiotic stress frequently influences phytohormone metabolism and signal transduction. Meanwhile, phytohormones play critical roles in responding to external and internal cues to regulate plant growth and development under abiotic stresses [10]. To further understand how M. falcata

Table 1 TFs differentially expressed due to abiotic stresses

\begin{tabular}{|c|c|c|c|c|c|c|}
\hline \multirow[t]{2}{*}{ TF family } & \multicolumn{2}{|l|}{ DS } & \multicolumn{2}{|l|}{ SS } & \multicolumn{2}{|l|}{ CS } \\
\hline & Increase & Decrease & Increase & Decrease & Increase & Decrease \\
\hline NAC & 62 & & 33 & & 12 & \\
\hline MYB-related & 30 & 19 & 17 & 9 & 16 & 12 \\
\hline bHLH & 32 & 20 & 18 & 2 & 9 & 3 \\
\hline AP2-EREBP & 26 & & 15 & 6 & 15 & 10 \\
\hline WRKY & 31 & 4 & 10 & 1 & 9 & 3 \\
\hline FAR1 & 19 & 8 & 6 & 2 & 6 & 3 \\
\hline MADS & 24 & & 10 & & 3 & \\
\hline Orphans & 25 & 2 & 10 & 1 & 7 & \\
\hline $\mathrm{C} 2 \mathrm{H} 2$ & 13 & 3 & 11 & 3 & 4 & 5 \\
\hline $\mathrm{C} 3 \mathrm{H}$ & 15 & 4 & 10 & 2 & 1 & \\
\hline G2-like & 4 & 12 & 3 & 2 & 2 & 4 \\
\hline Dof & & 6 & 8 & 7 & & 3 \\
\hline GRAS & 15 & & 2 & 1 & 1 & 3 \\
\hline bZIP & 10 & 2 & 5 & 3 & 1 & 5 \\
\hline SET & 12 & 1 & 8 & & 4 & \\
\hline PHD & 11 & 2 & 1 & & 1 & 1 \\
\hline Pseudo-ARR & 7 & 2 & 2 & 2 & 2 & \\
\hline LBD & 10 & & 4 & & 4 & \\
\hline ARF & 6 & 2 & 3 & & & \\
\hline
\end{tabular}

TFs with altered expression patterns between the abiotic-stressed samples and standard samples were used. The numbers of individual transcripts within a TF family exhibiting increased or decreased expression (a 2-fold or greater change) in the abiotic-stressed samples compared with the standard sample are shown 

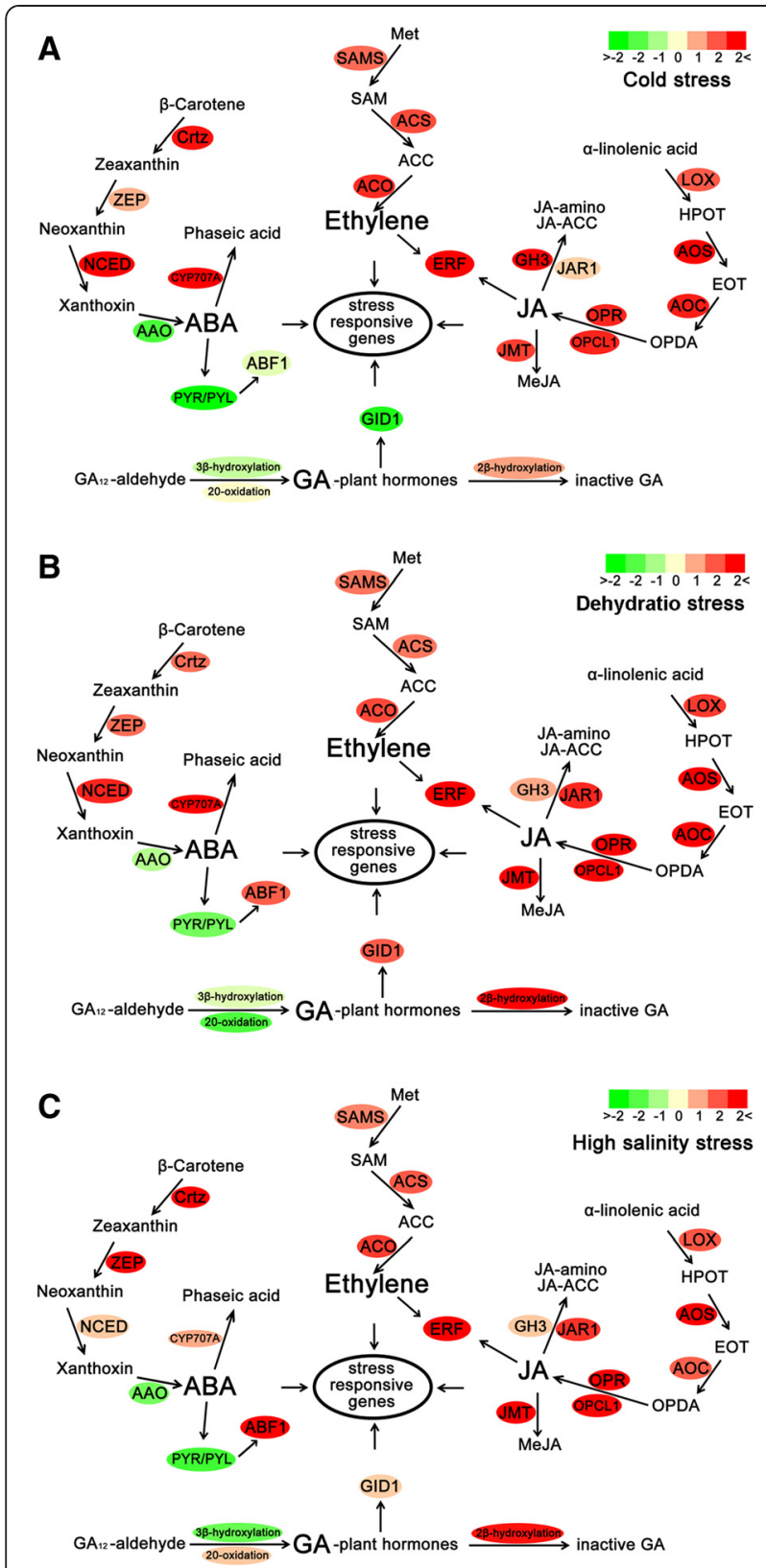

Fig. 2 Expression and pathway distribution of phytohormone metabolism and signal transduction-related genes in M. falcata. a Expression pattern of key genes under cold stress. $\mathbf{b}$ Expression pattern of key genes under dehydration stress. c Expression pattern of key genes under high salinity stress. Additional abbreviations are as follows: Crtz (beta-carotene 3-hydroxylase); ZEP (zeaxanthin epoxidase); NCED (9-cis-epoxycarotenoid dioxygenase); AAO (abscisic-aldehyde oxidase); PYR/PYL (PYRABACTIN RESISTANCE1 / PYRABACTIN RESISTANCE 1-LIKE) ABF1 (ABRE-binding factors 1); GID1 (GA-INSENSITIVE DWARF1); SAMS (S-adenosylmethionine synthetase); ACS (1-aminocyclopropane-1carboxylic acidsynthetase); ACO (1-aminocyclopropane-1-carboxylic acid oxidase); ERF (ethylene response factor); LOX (lipoxygenase); AOS (allene oxide synthase); AOC (allene oxide cyclase); OPR (12-oxophytodienoic acid reductase); OPCL1 (OPC-8:0 CoA ligase 1); JMT (jasmonate O-methyltransferase); and JAR1 (Jasmonate response 1). Filled colours correspond with their degree of regulation by the stresses acclimates to abiotic stresses, we evaluated our transcriptome data for differential expression genes to phytohormone metabolism and signal transduction, including abscisic acid (ABA), ethylene, jasmonic acid (JA), and gibberellins (GA) (Fig. 2).

ABA signalling and its key role in the adaptation of plants to stress conditions has been the focus of many studies since the early 1990s [76]. Thus, we queried the database for differentially expressed transcripts related to ABA biosynthesis enzymes, such as Crtz (beta-carotene 3-hydroxylase), ZEP (zeaxanthin epoxidase), and NCED (9-cis-epoxycarotenoid dioxygenase), as well as AAO (abscisic-aldehyde oxidase) and ABA catabolism enzymes, such as CYP707A (Fig. 2). As expected, most of the transcripts for the ABA biosynthesis enzyme genes displayed enhanced expression in DS, SS, and CS. However, transcripts for the ABA catabolism enzyme genes showed decreased expression in DS, SS, and CS. Unexpectedly, transcripts for the AAO gene, which encodes for an enzyme that catalyses the final step of ABA biosynthesis, showed different levels of decreased expression in all stress-treated samples. Meanwhile, we determined the content of $\mathrm{ABA}$ after cold treatment. Compared with M. truncatula, the content of ABA in M. falcata dropped significantly (Additional file 9). Furthermore, PYR/PYL (Pyrabactin Resistance 1/Pyrabactin Resistance 1-Like) genes, identified as ABA receptors, showed obvious decreased expression in DS, SS, and CS. $\mathrm{ABF}$ transcription factors are the key regulators of $\mathrm{ABA}$ signalling. Interestingly, transcripts for a member of this family, named ABF1, and exhibiting differential expression were found; up-regulated expression was observed in the DS and SS samples, while down-regulated expression was observed in the CS samples. Together with $\mathrm{ABA}$, gibberellins (GAs) act as a main regulating factor in seed germination; however, their role is antagonistic compared with ABA. A principal pathway for GA plant hormones can be drawn from $\mathrm{GA}_{12}$-aldehyde. A stepwise analysis of GA metabolism revealed the conversion of $\mathrm{GA}_{12}$-aldehyde to bioactive $\mathrm{GA}_{4}$ and inactive $\mathrm{GA}_{34}$ [77]. In our transcriptome data, the GA 20-oxidase and $3 \beta$-hydroxylase transcripts showed different levels of decreased expression in all stress-treated samples; however, the $2 \beta$-hydroxylase transcripts displayed the respective increased expression in these samples (Fig. 2). Interestingly, we identified some transcripts for a GA receptor named GID1 (GA-INSENSITIVE DWARF1) exhibiting differential expression. Compared with the down-regulated expression in the CS sample, these transcripts showed up-regulated expression in the DS and SS samples.

Our transcriptome data demonstrated that both ethylene and JA metabolism are altered under abiotic stress conditions. The biochemistry of ethylene biosynthesis has been a subject of intensive study in plant hormone physiology [78]. 
Major breakthroughs in the ethylene synthesis pathway were the establishment of S-adenosylmethionine (SAM) and 1-aminocyclopropane-1-carboxylic acid (ACC) as the precursors of ethylene. Based on this knowledge, we identified differentially expressed transcripts related to ethylene biosynthesis enzymes (Fig. 2). All of the transcripts for ethylene biosynthesis enzyme genes showed enhanced expression in the DS, SS, and CS samples. In addition, jasmonates are also important regulators in plant responses to abiotic stresses and in development [79]. The expression of the transcripts involved in JA biosynthesis was increased in the DS, SS, and CS samples (Fig. 2). Upon further analysis, we noted that all three abiotic stresses increased the expression of transcripts related to the JA metabolic pathway, which would contribute to the increased formation of the bioactive JA compound. Additionally, ethylene response factor (ERF) is an upstream component in both JA and ethylene signalling and is involved in abiotic stress resistance [80]. The transcripts for the ERF genes exhibited increased expression in DS, SS, and CS. A reconstruction of metabolic pathways based upon the expression profiles of transcripts expressed during phytohormone biosynthesis provides evidence for previously unrecognised abiotic stress-induced pathways and reinforces the interpretation that phytohormone metabolism is modified under abiotic stress conditions. The expression of transcripts involved in phytohormone metabolism and signal transduction was confirmed with qRT-PCR (Table 2).

Early reports suggested that auxin might affect plant stress response and abiotic stresses might regulate the expression of auxin-responsive genes [17, 81]. In our transcriptome data, few transcripts related to auxin biosynthesis showed differential expression. Interestingly, an auxin-responsive gene named GH3 was indentified up-regulated almost 16-fold in CS. To better understand the role of auxins in plant responses to cold stress and in root development, we treated plants with either indoleacetic acid (IAA) or cold stress (Fig. 3). The application of cold stress led to a dramatic reduction of lateral roots, nodule number, and root length. By comparison, the addition of IAA had no effect on root length; however, the number of lateral roots and nodules increased. To further investigate the mechanism underlying auxins in plant responses to cold stress and in root development, we used qRT-PCR to measure the expression levels of genes involved in auxin transport. Not surprisingly, cold application appeared to inhibit the expression of AUX, an important gene in auxin transport. The expression of AUX increased after the application of exogenous IAA. Overall, these qRT-PCR results illustrate the importance of auxin transport in M. falcata responses to cold stress and in root development.

Nodules are legume-specific organs that are formed to fix atmospheric nitrogen through the establishment of a symbiotic association with bacteria known as rhizobia. To investigate the effect of abiotic stresses on nodule formation, we identified differentially expressed transcripts related to nod factor signalling pathways during early symbiotic nodulation (Fig. 4). NFR1 and NFR5 have been recognised as nod factor receptors in a previous study [82]. Transcripts for the NFR1 and NFR5 genes showed different levels of increased expression in all stress-treated samples. DMI1 and DMI2 are two components of the nod factor signalling pathway upstream of calcium spiking. DMI3 is a component of the nod factor signalling pathway downstream of calcium spiking and is responsible for the conversion of the calcium spiking signal. In the DS and SS samples, the transcripts for the DMI1, DMI2, and DMI3 genes displayed similar increased expression levels. In the CS sample, the transcripts for the DMI1 gene exhibited upregulated expression. In contrast, the transcripts for the DMI2 and DMI3 genes exhibited down-regulated expression. ENOD11 is widely used as an early infectionrelated molecular marker for endosymbiotic associations involving both rhizobia and arbuscular mycorrhizal fungi [83]. Enod11 can be induced by several transcriptional regulators, including NSP1, NSP2, ERN1, and ERN2. The transcripts for the Enod11 gene exhibited obviously decreased expression in the DS, SS, and CS samples. In our transcriptome data, NSP1 and NSP2 displayed different levels of decreased expression in all stress-treated samples. ERN1 and ERN2 exhibited differential expression; up-regulation was found in the DS samples, while down-regulation was observed in the SS and CS samples. RRs (response regulators) act upstream of the NSP pathway to regulate the cytokinin response and nodule organogenesis [84]. The transcripts for the RRs genes exhibited obvious increased expression in the DS, SS, and CS samples. The expression level of the transcripts involved in the nod factor signalling pathways during early symbiotic nodulation was confirmed with qRTPCR (Table 2).

\section{RNA-Seq expression validation by qRT-PCR}

Transcripts known to be involved in the abiotic stress response (such as dehydration, high salinity, and cold) were confirmed by qRT-PCR to have expression patterns similar to those measured by RNA-Seq. Additionally, the expression profiles of transcripts involved in phytohormone metabolism and symbiotic nodulation signal transduction were also measured by qRT-PCR (Additional files 10 and 11). Finally, transcripts involved in auxin transport were identified in the assembly and used to design primers for qRT-PCR analysis to measure the expression profiles in plants treated with IAA. In total, 56 transcripts were evaluated by qRT-PCR, with $95.2 \%$ consistent with the RNA-Seq data (Table 2). 
Table 2 Confirmation of the RNA-Seq expression profiles with qRT-PCR

\begin{tabular}{|c|c|c|c|c|c|c|c|}
\hline Transcript & RNA-Seq(CS) & RNA-Seq(DS) & RNA-Seq(SS) & qRT-PCR(CS) & qRT-PCR(DS) & qRT-PCR(SS) & Annotation \\
\hline Mf53179 & 5.93 & 0.69 & 0.05 & 9.28 & 5.01 & 2.43 & DREB protein \\
\hline Mf40807 & 3.81 & 1.30 & 0.91 & 4.27 & 4.06 & 1.71 & $\mathrm{GH} 3$ \\
\hline Mf52262 & 2.79 & 3.45 & 2.16 & 7.24 & 8.87 & 5.47 & NFR5 \\
\hline Mf44686 & 2.55 & 6.14 & 2.35 & 7.62 & 7.03 & 3.19 & ERF \\
\hline Mf24843 & 2.45 & 5.53 & 3.08 & 7.28 & 9.46 & 5.09 & ERF \\
\hline Mf94524 & 2.22 & 3.83 & 0.66 & 4.43 & 3.25 & 0.45 & CYP707A \\
\hline Mf21376 & 2.18 & 1.70 & 0.40 & 2.13 & 1.57 & 0.33 & NCED \\
\hline Mf89827 & 2.17 & 4.92 & 5.37 & 1.74 & 6.17 & 5.14 & Stress-induced receptor \\
\hline Mf26361 & 2.11 & 2.72 & 1.95 & 1.84 & 4.19 & 0.43 & OPCL1 \\
\hline Mf20359 & 2.04 & 0.58 & 1.34 & 0.15 & 4.39 & 2.06 & ACS \\
\hline Mf40505 & 1.93 & 3.50 & 2.66 & 2.01 & 5.98 & 1.40 & OPR \\
\hline Mf51793 & 1.88 & 6.03 & 3.99 & 5.03 & 6.35 & 4.40 & Calmodulin binding \\
\hline Mf23563 & 1.86 & 1.12 & 2.39 & 1.86 & 1.12 & 2.40 & CrtZ \\
\hline Mf84393 & 1.49 & 3.81 & 2.09 & 3.76 & 4.96 & 3.95 & JMT \\
\hline Mf42223 & 1.48 & 3.83 & 1.88 & 4.74 & 4.71 & 1.66 & AOS \\
\hline Mf34249 & 1.40 & 1.88 & 1.29 & 3.81 & 1.02 & 1.43 & ACS \\
\hline Mf84453 & 1.28 & 1.53 & 1.31 & -0.16 & 1.05 & -2.60 & LOX \\
\hline Mf31223 & 1.26 & 1.52 & 1.24 & 1.74 & 3.19 & 0.05 & $\mathrm{AOC}$ \\
\hline Mf37052 & 1.24 & 3.75 & 3.10 & 2.81 & 2.83 & 1.09 & NFR1 \\
\hline Mf19438 & 1.21 & 2.24 & 1.65 & 5.07 & 3.66 & 1.07 & SAMS \\
\hline Mf21208 & 1.16 & 1.68 & 1.12 & 0.70 & 3.28 & 1.34 & 2-beta-dioxygenase \\
\hline Mf37096 & 1.15 & 4.29 & 2.69 & 1.03 & 3.22 & 0.23 & DMI3 \\
\hline Mf46196 & 1.09 & 4.29 & 5.05 & 3.56 & 10.67 & 9.19 & NCED \\
\hline Mf41585 & 1.08 & 1.51 & 1.14 & 0.10 & 1.95 & -1.19 & SNF1 \\
\hline Mf84582 & 0.96 & -1.01 & 0.29 & -0.52 & -2.24 & -2.72 & cytochrome P450 \\
\hline Mf19924 & 0.96 & 3.13 & 1.70 & 1.18 & 0.89 & 0.64 & SAMS \\
\hline Mf35541 & 0.83 & 2.21 & 1.65 & 0.26 & 1.46 & -1.00 & SNF1 \\
\hline Mf53098 & 0.75 & 1.69 & 1.60 & 0.32 & 1.67 & 0.43 & JAR1 \\
\hline Mf52729 & 0.70 & -0.38 & 0.46 & 5.19 & -0.63 & 3.87 & Cysteine-rich receptor \\
\hline Mf29322 & 0.65 & 0.91 & 1.75 & 1.69 & 1.25 & 1.20 & $\mathrm{ACO}$ \\
\hline Mf32232 & 0.59 & 1.13 & 3.02 & -0.04 & 1.13 & 3.01 & ZEP \\
\hline Mf46161 & 0.49 & 3.69 & 1.20 & 2.24 & 3.79 & 0.46 & ACS \\
\hline Mf33973 & 0.42 & 1.21 & 0.25 & 2.01 & 1.73 & 0.69 & DMl1 \\
\hline Mf22267 & 0.18 & 0.45 & -0.53 & 0.43 & 0.40 & -0.87 & CrtZ \\
\hline Mf37546 & 0.15 & 1.34 & 0.78 & 0.30 & 0.25 & -0.61 & JAR1 \\
\hline Mf24274 & 0.14 & -0.68 & -0.40 & 0.07 & -1.38 & -0.26 & 20-oxidase \\
\hline Mf58069 & 0.11 & 0.48 & 1.82 & 1.03 & 0.17 & 1.15 & $\mathrm{ACO}$ \\
\hline Mf88132 & -0.21 & 1.26 & 2.37 & -0.66 & 2.33 & 2.90 & ABF 1 \\
\hline Mf46174 & -0.25 & -1.17 & -0.25 & -1.11 & -0.95 & -0.41 & ZEP \\
\hline Mf23784 & -0.77 & -0.72 & -1.00 & -1.93 & -0.06 & -0.42 & NSP11 \\
\hline Mf49154 & -0.95 & 0.58 & 1.87 & -0.56 & 2.59 & 3.75 & Importin \\
\hline Mf50824 & -0.96 & 3.51 & 1.26 & -0.79 & 1.20 & 0.70 & DMI2 \\
\hline Mf54137 & -1.11 & 1.41 & 0.18 & -3.07 & 5.33 & 3.96 & Nodule receptor kinase \\
\hline Mf22751 & -1.33 & -1.76 & -0.74 & -0.46 & -0.73 & -1.25 & PYR/PYL \\
\hline
\end{tabular}


Table 2 Confirmation of the RNA-Seq expression profiles with qRT-PCR (Continued)

\begin{tabular}{llllllll}
\hline Mf1 1674 & -1.36 & -2.59 & -0.26 & -0.68 & -1.45 & -2.58 & Leghemoglobin \\
Mf24497 & -1.49 & -0.88 & -1.62 & -3.93 & -0.23 & -2.52 & ENOD \\
Mf34644 & -1.54 & 0.43 & 0.14 & -0.55 & 0.99 & 0.60 & GID1 \\
Mf20666 & -1.76 & 1.26 & 0.37 & -0.16 & 0.92 & 0.20 & GID1 \\
Mf56011 & -1.77 & -1.09 & -0.47 & -2.17 & -2.48 & -1.62 & AAO \\
Mf38812 & -2.21 & 2.13 & 2.99 & 0.52 & 0.68 & 0.72 & DMI3 \\
Mf17441 & -2.26 & -1.66 & -2.11 & -1.45 & -0.71 & -1.14 & AAO \\
Mf87623 & -2.45 & -1.08 & -1.48 & -1.04 & -0.35 & -2.13 & PYR/PYL \\
Mf49788 & -3.16 & -2.17 & -2.18 & -0.70 & -0.57 & -2.60 & NSP2 \\
Mf20500 & -3.78 & 3.32 & -0.57 & -1.98 & 5.88 & -2.94 & ERN2 \\
Mf21830 & -4.11 & -1.75 & -2.31 & -1.84 & -0.73 & -4.88 & ENOD \\
Mf29128 & -5.20 & 1.10 & -0.12 & -0.46 & -0.05 & -1.69 & 3 -beta-hydroxylase
\end{tabular}

The expression levels of CS, DS, SS, and SC were calculated, and pairwise comparisons (CS versus SC, DS versus SC, and SS versus SC) were calculated. Expression ratios for the RNA-Seq data, shown as the fold change, were calculated for cold [RNA-Seq (CS)], dehydration [RNA-Seq (DS)], and high salinity [RNA-Seq (SS)] using the DESeq programme. Ratios for qPCR analyses were calculated for cold [qRT-PCR (CS)], dehydration [qRT-PCR (DS)], and high salinity [qRT-PCR (SS)] using a previously described method [114]. All expression ratios are presented as $\log _{2}($ treatment/standard). Negative values indicate that the standard has a higher expression level than the treatment, and expression ratios of 0 indicate no difference in expression between the treatment and standard

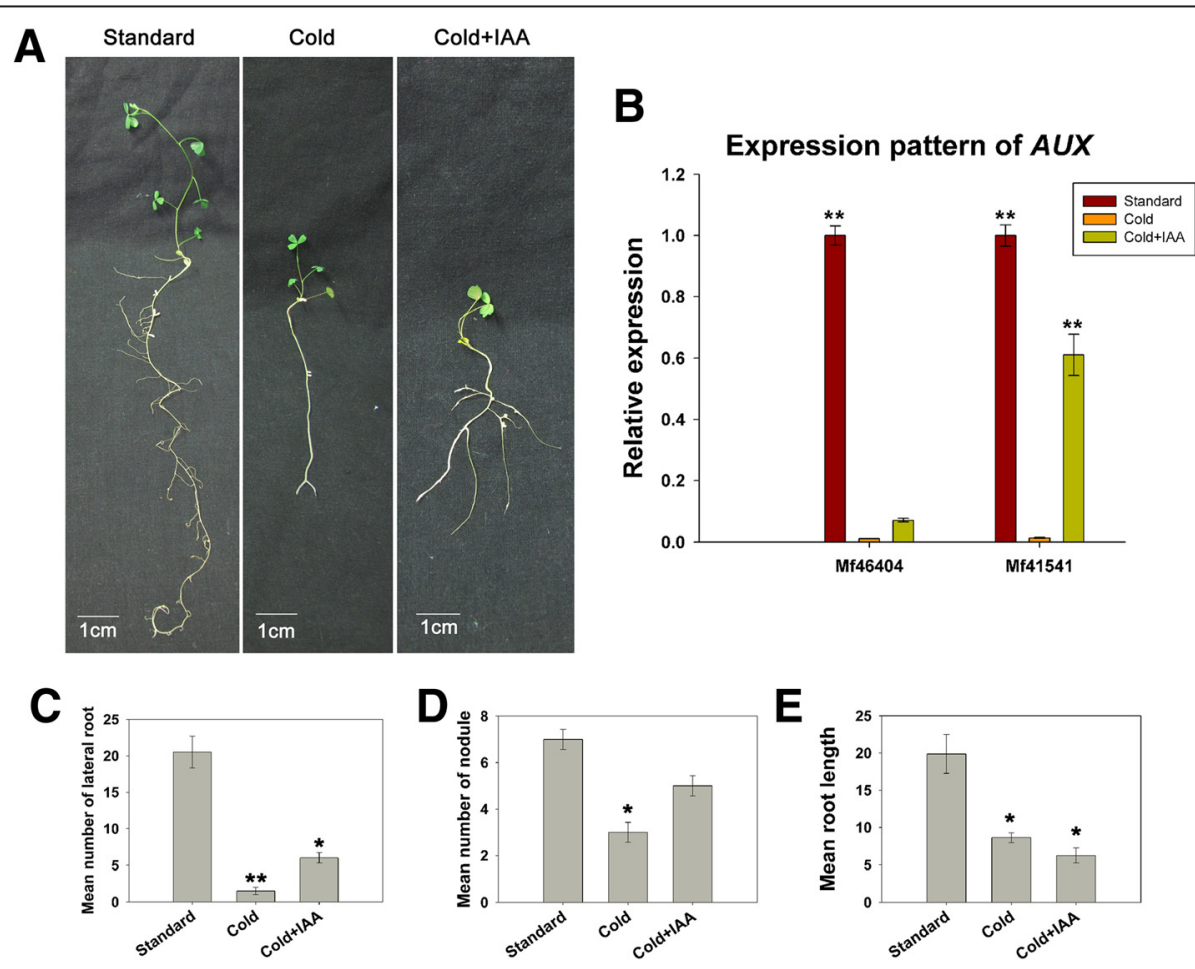

Fig. 3 Auxin application influences cold stress-induced root development. a Standard condition, cold treatment, and cold treatment with IAA application phenotypes of $M$. falcata. b Relative expression level of genes coding for the auxin transporter (AUX). c Number of lateral roots under standard conditions, cold treatment, and cold treatment with IAA application. The mean values and SD were calculated from the results of the three replicated experiments. (Student's $t$-test, ${ }^{*} P<0.001,{ }^{*} P<0.01$ ). d Number of nodules under standard conditions, cold treatment, and cold treatment with IAA application. The mean values and SD were calculated from the results of three replicated experiments. (Student's $t$-test, ${ }^{* *} P<0.001,{ }^{*} P<0.01$ ). e Length of root under standard conditions, cold treatment, and cold treatment with IAA application. The mean values and SD were calculated from the results of the three replicated experiments. (Student's $t$-test, ${ }^{*} P<0.001,{ }^{*} P<0.01$ ) 

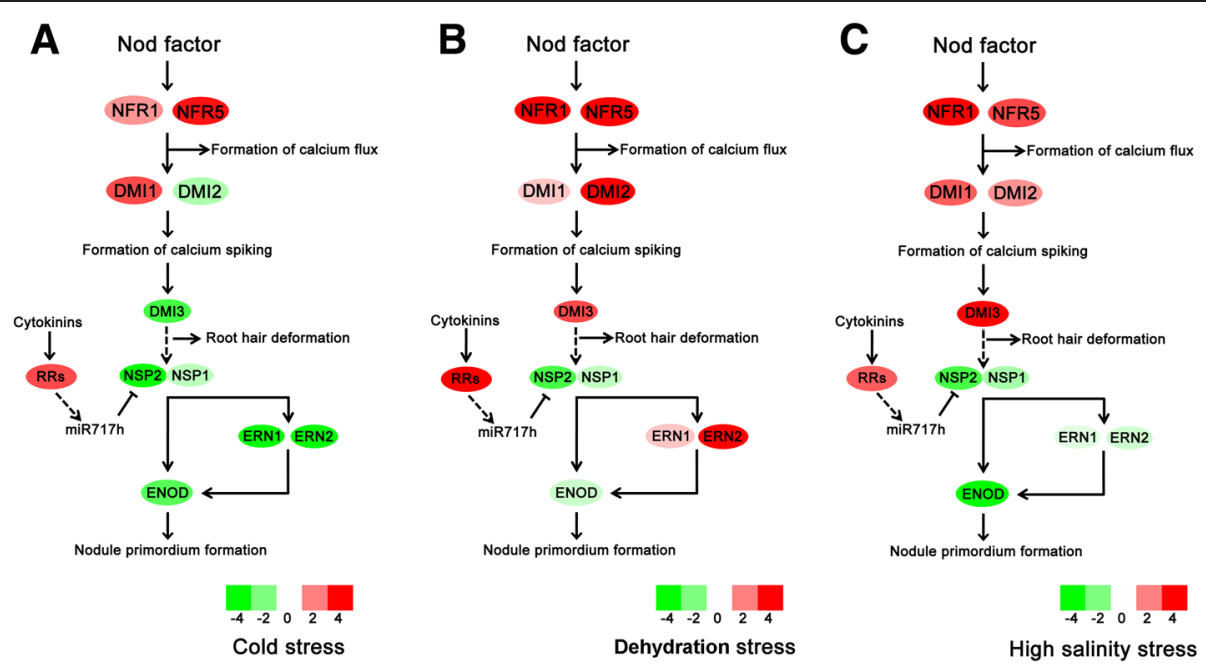

Fig. 4 Expression pattern of genes involved in early symbiotic nodulation. a Expression pattern of key genes under cold stress. $\mathbf{b}$ Expression pattern of key genes under dehydration stress. c Expression pattern of key genes under high salinity stress. Additional abbreviations are as follows: NFR (nod factor receptor); DMI (does not make infections); NSP (Nodulation signalling pathway); ERN (ERF required for nodulation); and ENOD (early nodule). Filled colours correspond with their degree of regulation by the stresses

\section{Comparative transcriptomics of $\mathrm{M}$. falcata and with the other legume species}

Previous phylogenetic analyses of the legumes have divided the family into seven major clades: Cladrastis, genistoidsensulato, dalbergioidsensulato, mirbelioid, millettioid, robinioid, and inverted-repeat-lacking (IRLC) [85]. Medicago truncatula is a member of the IRLC clade and is closely related to M. falcata (Fig. 5a). To explore the relationship between $\mathrm{M}$. falcata and other legumes at the transcriptome level, we compared the assembled and translated M. falcata transcriptome to a peptide database derived from the sequenced genomes of Medicago truncatula, Cicer arietinum, Lotus japonicas, Glycine max, Phaseolus vulgaris, and Cajanus cajan. A BLASTx comparison of the $\mathrm{M}$. falcata transcriptome to this peptide database showed that $35,513 \mathrm{M}$. falcata contigs had significant $\left(\mathrm{e} \leq 1 \mathrm{e}^{-5}\right)$ top hits to M. truncatula (Fig. 5b). C.arietinum had the next highest number of top hits $(9,614)$. A BLASTx comparison of the remaining sequences without significant hits to one of the six legume species revealed
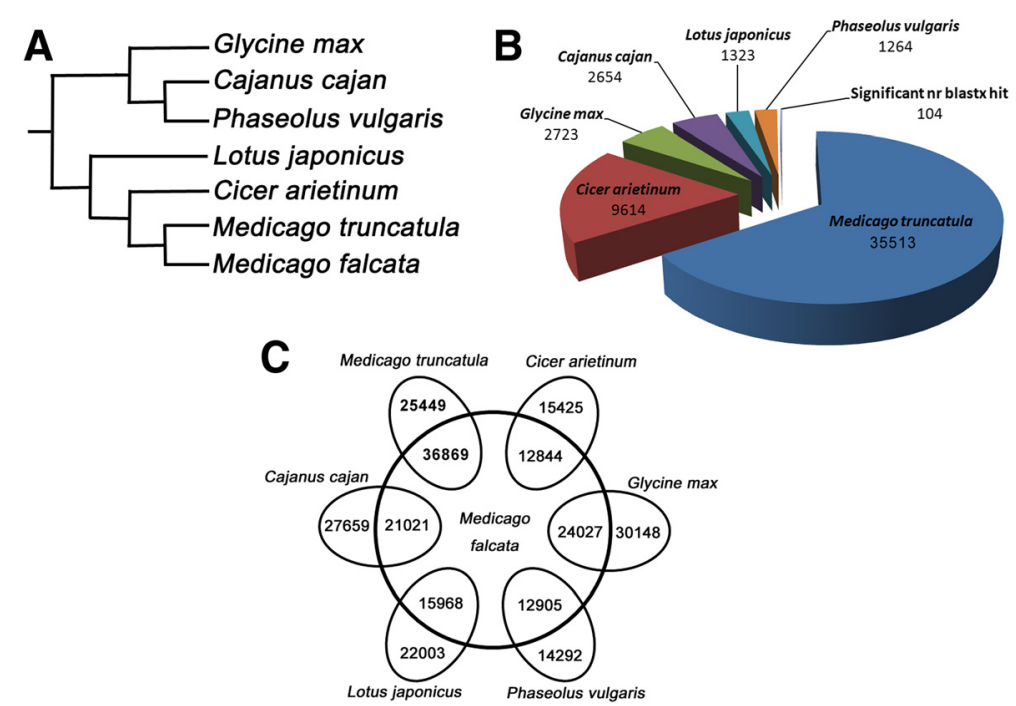

Fig. 5 Comparative transcriptomics of $M$. falcata with six leguminous species. a Representation of the legume phylogeny. b BLASTx comparison of the M. falcata transcriptome assembly with M. truncatula, C. arietinum, G. max, C. cajan, L. japonicus, and P. vulgaris. The top BLAST hit (e $\leq 10-5)$ for each M. falcata transcript to the six species is shown. Contigs without significant hits were then compared with the NCBI peptide non-redundant (nr) database. c Six pairwise tBLASTn comparisons of legume species to the $M$. falcata transcriptome assembly. Sequences with significant homology (e $\leq 10-5$ and positive percent $\geq 70 \%$ ) shared between the six legume species and $M$. falcata are shown on the inner circle 
that 104 sequences had significant hits in the NCBI nonredundant (nr) peptide database.

To examine the degree of conservation between $\mathrm{M}$. falcata and other sequenced legume species, six pairwise tBLASTn comparisons were performed between M. falcata and each of the six legume species (Fig. 5c). M. truncatula had the highest number of sequences with significant hits to the $M$. falcata database $\left(\mathrm{e} \leq 1 \mathrm{e}^{-5}\right.$ and $\geq 70 \%$ positive match percent), and the greatest proportion of peptides with significant matches $(36,869 / 62,318)$. All six species had at least $42 \%$ of their proteins significantly represented in the M. falcata database. A global view of the top M. falcata transcripts and their similarity to each $\mathrm{M}$. truncatula peptide (primary transcripts only) is shown in Additional file $12 \mathrm{C}$. Of the M. truncatula loci, 6,743 of 62,318 had transcripts with $>70 \%$ similarity and $>70 \%$ coverage in the M. falcata transcriptome.

To more closely examine the level of global sequence conservation between $M$. falcata and $M$. truncatula, we further examined a BLASTx comparison of the M. falcata transcriptome assembly with the $M$. truncatula peptide database (primary transcripts only). The relative homology of each predicted peptide to the most similar $M$. truncatula protein was measured by the percent of positive sequence similarity (Additional file 12A) and percent coverage (Additional file 12B). A smooth scatter plot representing the percent similarity and percent coverage for each $\mathrm{M}$. falcata sequence compared with the closest $\mathrm{M}$. truncatula peptide sequence is shown in Additional file $12 \mathrm{C}$. A proportion $(>40 \%)$ of transcripts possessed at least $70 \%$ similarity to a $\mathrm{M}$. truncatula protein. A total of $13,538 \mathrm{M}$. falcata transcripts had at least one match to a $\mathrm{M}$. truncatula gene, with $>70 \%$ similarity $/>70 \%$ coverage. Of the M. falcata transcripts, 1,454 had $\geq 95 \%$ similarity and coverage, 2,029 transcripts were between 80-95\% similarity and coverage, 730 transcripts were between $70-80 \%$ similarity and coverage, 7,458 transcripts were $<70 \%$ similarity and coverage, and 49,400 transcripts lacked a significant BLASTx hit $\left(e \leq 1 \mathrm{e}^{-5}\right)$ to a M. truncatula peptide.

\section{Discussion}

Several studies utilising microarrays and RNA-Seq have documented the responses of plants to abiotic stresses. In this study, we extended our fundamental understanding of plant acclimation to abiotic stresses through an RNA-Seq whole transcriptome analysis of dehydration, high salinity, and cold treatment in M. falcata. Although our analysis primarily focused on phytohormone metabolism and signalling, we also explored the effect of abiotic stresses on nod factor signalling pathways during early symbiotic nodulation. Our data provide the foundation for what to our knowledge is the first M. falcata gene index (MFGI). We report 98,515 unique sequences, of which more than 6,000 respond to abiotic stresses. Moreover, we report previously unrecognised transcriptional responses to abiotic stresses.

\section{Comparing the M.falcata transcriptome with other legume transcriptomes}

We sequenced, assembled, and annotated the M. falcata transcriptome. The draft transcriptome consists of 98,515 unique sequences, of which 51,040 were annotated and the functions of the rest transcripts were unknown. Of these transcripts, $34.5 \%$ were most similar to M. truncatula genes, and $52 \%$ had top hits in the legume, indicating a high level of sequence conservation across the family. BLAST comparisons between M. falcata and six other sequenced legume species showed that our M. falcata transcriptome has good coverage of homologous sequences. Compared with the other species, M. truncatula had the largest proportion of peptides with significant matches $(36,869 / 62,318)$. In total, all of these six species had 107,779 proteins significantly represented in the $M$. falcata database. We inferred that multiple sequences in the $\mathrm{M}$. falcata assembly may divide from one single protein-coding transcript. These analyses are consistent with previous phylogenetic findings that $\mathrm{M}$. falcata is more closely related to $\mathrm{M}$. truncatula than other species [85]. The M. falcata transcriptome will provide evidence for the expression of predicted genes in the $M$. truncatula genome.

\section{Genes commonly expressed under abiotic stresses}

We identified 166 transcripts containing sequences homologous to 71 identified helicase proteins in other plants. Nine transcripts were induced by all three stresses. These transcripts were homologous to seven helicase proteins in plants, including Ricinus communis, Vitis vinifera, and Arabidopsis lyrata, indicating that at least seven helicase genes in M.falcata could be induced to respond to dehydration, high salinity, and cold. The helicase involved in the abiotic stress response was first identified in the legume pea [86]. In the pea, DNA helicase 47 (PDH47, GenBank accession number: AAN74636.1) was only induced by salt and cold stress and not by dehydration stress. This induction was also tissue-specific and regulated by responses to heat and ABA stress. In our data, three transcripts were similar to a DEAD-box ATPdependent RNA helicase (GenBank accession number: XP_002527090.1), and one transcript was similar to a RNA helicase (GenBank accession number: AAF40306.1). The importance of RNA helicases in stress responses was also reviewed in a previous research study [87]. An increased expression level was also observed in genes encoding for RNA polymerases. Eight transcripts corresponding to eight proteins from four species were induced 
by all three stresses and accounted for $2.8 \%$ of all of the polymerase transcripts identified. The relationship between poly (ADP-ribose) polymerase (PARP) and abiotic stresses has been studied in the soybean, and this enzyme was found to mediate DNA repair and programmed cell death processes during responses to mild and severe stresses, respectively [88]. In addition, PARP inactivation has been reported to increase the tolerance of plants against a broad range of abiotic stresses by inhibiting the processes of cell death and reducing energy consumption [89]. Choline, an important precursor of the membrane phospholipid phosphatidylcholine, is used to produce glycine betaine, which functions as an osmoprotectant conferring salt, drought, and other stress tolerance in plants [90, 91]. Phosphoethanolamine N-methyltransferase (PEAMT, EC 2.1.1.103) is believed to be a key enzyme of the choline biosynthesis pathway. Note that two transcripts with sequences homologous to a putative PEAMT protein from R. communis were upregulated by all three stresses.

\section{TF expression is altered by abiotic stresses}

Interestingly, all the major TF families induced by abiotic stresses are directly related to either a general stress response (NAC, MYB, bHLH, and WORKY) or a specific hormone pathway (AP2-EREBP, ARF, and PseudoARR). The largest class of TFs induced by abiotic stresses in the three stressed samples was the NAC TF family. A total of 62, 33, and 12 NACs were up-regulated due to dehydration, high salinity, and cold stress, respectively. NAC is regarded as a plant-specific transcription factor family member and expressed in many tissues and during many developmental stages [92]. A further systemic analysis of the NAC transcription factor family at the genome-wide level reported that approximately $30 \%$ of members of the NAC family are up-regulated during abiotic stress in rice, with 11 members induced by at least three types of abiotic stresses [93]. Additionally, in our data, the largest class of TFs induced by cold stress was the MYB TF family. A total of 16 MYBs were up-regulated by cold stress, suggesting that this TF family plays a major role in cold tolerance. A R2R3-type MYB has been identified as a master regulator of the cold stress response [94], and these results are consistent with our RNA-Seq data. Interestingly, in our transcriptome data, lower numbers of TFs were upregulated by cold stress than the other two stresses, potentially because the response to cold stress appears to be less active than dehydration and salt stresses. In our opinion, because $M$. falcata was originally grown in extremely cold environments, the cold-responsive genes were already expressed at a higher level. This hypothesis was inspired by a study in Arabidopsis and salt cress, which illustrated that the stress tolerance of salt cress was due to stress-inducible genes that were constitutively overexpressed in salt cress but inducible in Arabidopsis [95].

\section{Abiotic stresses modify phytohormone metabolism and signal transduction}

Previous studies have demonstrated that abiotic stresses have a striking effect on phytohormone metabolism and signalling. Transcriptomic and metabolomic analyses have demonstrated increased ABA, ethylene, and JA metabolism in several plants [12-20]. We not only reconfirm these initial findings but also extend our understanding of modified phytohormone metabolism in plants. The process from stress signal perception and the trigger of ABA biosynthesis to the dynamic regulation of the ABA level is an important stress signalling pathway in cells. Our data demonstrate the enhanced transcript expression involved in most steps of ABA biosynthesis, including transcripts for Crtz, ZEP, and NCED. The enhanced expression of ABA biosynthesis pathway genes may lead to increased endogenous $A B A$. Interestingly, transcripts for the AAO gene, which encodes for an enzyme that catalyses the final step of ABA biosynthesis, showed decreased expression in all stress-treated samples. Meanwhile, transcripts for the CYP707A gene, which encodes for an enzyme that catalyses ABA catabolism, showed increased expression in all stress-treated samples. Together with the ABA content determined under cold stress, we hypothesise that increased endogenous $A B A$ may inhibit ABA biosynthesis and advance ABA catabolism to some extent, which is aimed at the dynamic regulation of the ABA level and maintaining the ABA level in balance. ABA perception through PYR/PYL receptors is required for the basal ABA signalling that promotes plant growth and normal seed production and that regulates steady state transpiration [96]. The expression of transcripts for PYR/ PYL genes was inhibited by all three stressed samples. Compared with cold stress, the dehydration and high salinity stresses both enhanced the expression of the ABF1 genes observably and induced the expression of ABAresponsive genes further. In contrast, compared with enhancing ABA biosynthesis, all three abiotic stresses inhibited the conversion of $\mathrm{GA}_{12}$-aldehyde to bioactive $\mathrm{GA}_{4}$ and advanced the conversion of bioactive $\mathrm{GA}_{4}$ to inactive $\mathrm{GA}_{34}$, indicating that GA plays an antagonistic role in response to abiotic stresses in M. falcata compared with ABA. Additionally, the antagonistic role of GA is further confirmed by the expression pattern of GA receptors, namely GID1, being contrary to ABA receptors in the DS and SS samples.

The process from stress signal perception to the dynamic regulation of ethylene and JA metabolism is an important abiotic stress signalling pathway in plants. Compared with the downstream events in ethylene and JA signal transduction, the studies in this field are relatively lagging. Our discovery sheds new light on abiotic stress-induced ethylene and JA metabolic responses. We 
found evidence for pathways that lead to enhanced ethylene and JA biosynthesis. In our transcriptome data, we detected three key enzymes related to the ethylene biosynthesis pathway. All of the transcripts for ethylene biosynthesis enzyme genes showed enhanced expression in all three stressed samples. Consistent with ethylene, JA biosynthesis-related transcripts exhibited similar expression patterns. Upon further analysis, we noted that all three abiotic stresses increased the abundance of transcripts related to the JA metabolic pathway, which would contribute to the increased formation of the bioactive JA compound. Based on this knowledge, we infer that ethylene and JA have synergistically positive effects on resisting abiotic stresses. The ERF gene is an upstream component in both JA and ethylene signalling. The expression pattern of the ERF gene was also upregulated, further supporting our hypothesis.

\section{Abiotic stresses modify the nod factor signalling pathways during early symbiotic nodulation}

Early symbiotic nodulation involves four major developmental programmes: (1) the perception of nod factor, (2) the activation of calcium spiking, (3) root hair deformation and infection, and (4) early nodulin gene induction and nodule primordium formation. A comprehensive transcriptomic analysis of nodulation signalling pathway gene expression in response to abiotic stresses is lacking in the literature. We detected several transcripts for key genes involved in the nodulation signalling pathway. NFR genes are nod factor receptors and play a crucial role in the perception of nod factor. All three stresses increased the expression of the NFR genes. The DMI1 and DMI2 genes displayed similar expression patterns. In accordance with biotic stress, we hypothesise that all three abiotic stresses may enhance the perception of nod factor and the activation of calcium spiking. DMI3, which exhibits different expression patterns between abiotic stresses, may affect the perception of calcium spiking and deformation of root hairs. The expression of the DMI3 genes was down-regulated in the CS sample but up-regulated in the DS and SS stressed samples. The expression of the ENOD genes was down-regulated all together by the three stresses because the expression pattern of the ENOD transcriptional regulators ERN and NSP were altered by these stresses. NSP genes exhibiting decreased expression levels were predominantly due to the up-regulated RR genes. We hypothesise that NSP genes are targets of the RRs-dependent signalling pathway and that miR171h gene is crucial to regulate their expression in response to abiotic stresses and during early nodule development. Interestingly, the expression of the ENOD genes showed less of a decrease in the dehydration -stressed sample compared with the other two stressed samples, which may be due to the increased expression of ERN genes. Upon the above analyses, we concluded that all three stresses might negatively regulate the formation of nodule primordia.

\section{The role of auxin in root responses to cold stress}

The cold-stressed root transcripts reported here were derived from our RNA-Seq data and thus reflect the expression of genes not only involved in a generalised root response to cold stress but also transcripts directly related to root development. We found that cold stress reduced lateral root formation, nodule number, and root length. In addition, we found that IAA application can increase the number of lateral roots and nodules, suggesting that the cold-induced decrease of lateral root formation and nodule number are dependent upon a reduction in auxin availability. AUX is an important auxin transporter. Our qTR-PCR results indicate that cold application appears to inhibit AUX expression. The expression of AUX increased after the application of exogenous IAA. We hypothesise that cold-induced reductions in auxin availability may depend on the decreased expression levels of AUX genes. Interestingly, IAA application is unable to increase the length of the main root. We hypothesise that the development of the main root requires the synergy of auxins and other hormones.

\section{Conclusions}

To our knowledge, we here present the first whole transcriptome analysis of abiotic stresses using M. falcata and an in-depth RNA-seq analysis of its transcriptomes under optimal treatment conditions. Overall, these experiments and results have confirmed previously reported responses to abiotic stresses while addressing previously unknown details and fundamentally advancing our understanding of how modified gene expression patterns facilitate acclimation to abiotic stresses. We revealed the abiotic stress-responsive mechanisms underlying the metabolism and core signalling components of major phytohormones. In addition, we identified nod factor signalling pathways during early symbiotic nodulation that are modified by abiotic stresses.

\section{Methods}

\section{Plant material}

M. falcata seeds were obtained from the Agricultural Research Service (ARS) GRIN system (http://www.ars-grin. gov/), US Department of Agriculture (USDA). Seeds originating from Russia (accession number PI502449) were used for this work. Accession PI502449 is regarded as the most tolerant to winter injury [97] and was identified as diploid M. falcata [98]. Seeds of Medicago truncatula A17 and R108 were provided by BRC, UMR 1097, INRA, Montpellier, France. Seed treatments for germination have 
been published previously [97]. After germination, the plantlets were grown in a soil/vermiculite $(3: 1, \mathrm{v} / \mathrm{v})$ mixture in a chamber incubated under controlled environment conditions (14-h photo-period, $60 \mu \mathrm{mol}$ photons $\mathrm{m}^{-2} \mathrm{~s}^{-1}$, $22^{\circ} / 18^{\circ} \mathrm{C}$ day/night regime, $70 \%$ relative humidity).

\section{Evaluate the effect of cold, drought and salt stresses on M. truncatula 108-R, M. truncatula A17 and M.falcata PI502449}

Plants grown for these assays were germinated as described above. After germination, 4-week-old plants grown in a soil/vermiculite $(3: 1, \mathrm{v} / \mathrm{v})$ mixture at $24{ }^{\circ} \mathrm{C}$ under a 14-h photoperiod were used for abiotic stress treatments (14-h photo-period, $60 \mu \mathrm{mol}$ photons $\mathrm{m}^{-2} \mathrm{~s}^{-1}$, $22^{\circ} / 18{ }^{\circ} \mathrm{C}$ day/night regime, $70 \%$ relative humidity). For cold treatment, the plantlets were incubated at $0{ }^{\circ} \mathrm{C}$ (freezing chamber RuMED4001) for $6 \mathrm{~h}, 8 \mathrm{~h}$, and $10 \mathrm{~h}$ under dim light $\left(0.7-0.8 \mu \mathrm{mol} \mathrm{sec} \mathrm{sec}^{-1} \mathrm{~m}^{-2}\right)$. For drought treatment, the plants were grown without watering for $10 \mathrm{~d}, 12 \mathrm{~d}$, and $14 \mathrm{~d}$ under dim light (0.7-0.8 $\mu \mathrm{mol} \mathrm{sec} \mathrm{se}^{-1} \mathrm{~m}^{-2}$. For salinity treatment, the plants were irrigated with $\mathrm{NaCl}$ solution at $100 \mathrm{mM}$, $150 \mathrm{mM}$, and $200 \mathrm{mM}$ for $10 \mathrm{~d}$ under dim light (0.7$0.8 \mu \mathrm{mol} \mathrm{sec}^{-1} \mathrm{~m}^{-2}$ ). After treatment, leaves and roots were collected respectively, and then measured the weight, mortality and soluble carbohydrates content. Three independent experiments were performed.

\section{Electrolyte leakage assays}

Plants grown for electrolyte leakage assays were germinated as described above. After germination, 4-week-old plants grown in a soil/vermiculite $(3: 1, \mathrm{v} / \mathrm{v})$ mixture at $24{ }^{\circ} \mathrm{C}$ under a 16 -h photoperiod were used for abiotic stress treatments (14-h photo-period, $60 \mu \mathrm{mol}$ photons $\mathrm{m}^{-2} \mathrm{~s}^{-1}, 22^{\circ} / 18{ }^{\circ} \mathrm{C}$ day/night regime, $70 \%$ relative humidity). For cold treatment, the plantlets were incubated at $0{ }^{\circ} \mathrm{C}$ (freezing chamber RuMED4001) for $2 \mathrm{~h}, 4 \mathrm{~h}, 6 \mathrm{~h}$, $8 \mathrm{~h}$, and $10 \mathrm{~h}$ under dim light $\left(0.7-0.8 \mu \mathrm{mol} \mathrm{sec}^{-1} \mathrm{~m}^{-2}\right)$. For dehydration treatment, the plantlets were transferred to dry Whatman $3 \mathrm{MM}$ paper [4] for $0.5 \mathrm{~h}, 1 \mathrm{~h}, 1.5 \mathrm{~h}$, and $2 \mathrm{~h}$ under dim light $\left(0.7-0.8 \mu \mathrm{mol} \mathrm{sec}^{-1} \mathrm{~m}^{-2}\right)$. For high salinity treatment, the plantlets were irrigated with $\mathrm{NaCl}$ solution at $200 \mathrm{mM}, 400 \mathrm{mM}, 600 \mathrm{mM}, 800 \mathrm{mM}$, and $1 \mathrm{M}$ for $2 \mathrm{~h}$ under dim light $\left(0.7-0.8 \mu \mathrm{mol} \mathrm{sec}{ }^{-1} \mathrm{~m}^{-2}\right)$. After treatment, leaves were collected, and the electrolyte leakage was measured as previously described [97]. Three independent experiments were performed.

\section{Abiotic stress treatment for sequencing samples}

Plants grown for abiotic stress treatment were germinated as described above. Dehydration, cold, and high salinity stress treatments were applied essentially as reported previously [99]. For dehydration treatment, plants were harvested from pots and desiccated on Whatman
$3 \mathrm{MM}$ paper for $2 \mathrm{~h}$ at $24{ }^{\circ} \mathrm{C}$ under dim light (0.7$\left.0.8 \mu \mathrm{mol} \mathrm{sec}^{-1} \mathrm{~m}^{-2}\right)$. For cold stress, we transferred the plantlets to $0{ }^{\circ} \mathrm{C}$ (freezing chamber RuMED4001) for $8 \mathrm{~h}$ under dim light $\left(0.7-0.8 \mu \mathrm{mol} \mathrm{sec}{ }^{-1} \mathrm{~m}^{-2}\right)$. For high salinity stress, we irrigated the plantlets with $1 \mathrm{M} \mathrm{NaCl}$ solution for $2 \mathrm{~h}$ under dim light $\left(0.7-0.8 \mu \mathrm{mol} \mathrm{sec}^{-1} \mathrm{~m}^{-2}\right)$. Plantlets without stress treatment were used as the standard condition, and all materials were stored in liquid nitrogen immediately after treatment and harvest. Two biological replicates per condition were used for further analysis. In every biological replicate, we mix five plantlets together.

\section{cDNA library preparation and sequencing}

Total RNA from each sample was isolated using the TRIzol reagent (Invitrogen), and genomic DNA was digested using DNase (New England Biolabs). We used the OligoTex mRNA mini kit (Qiagen) to purify poly (A) mRNA from the total RNA. The protocol for cDNA synthesis has been previously described [100]. The mRNA was fragmented using an RNA fragmentation kit (Ambion). The first cDNA strand was synthesised using random hexamer primers, and the second cDNA strand was subsequently synthesised.

The sequencing library was constructed according to the manufacturer's instructions (Illumina) for highthroughput sequencing. Fragments of approximately 300 nt were excised and enriched by 18 PCR cycles. The PCR products were sequenced using the Illumina HiSeq 2000 platform using101-cycle paired-end reads. Initial base calling and quality filtering of the Illumina GA-IIx image data were performed using the default parameters of the Illumina GA Pipeline GERALD stage (http://www.illumina.com). All sequencing reads were deposited into the Short Read Archive (SRA) of the National Center for Biotechnology Information (NCBI), and can be accessed under the accession number (SRR1956534, SRR1956535, SRR1956716, SRR1956718, SRR1956719, SRR1957050, SRR1956913, SRR1956721, SRR1982256, SRR1982261, SRR1982264 and SRR1982268).

\section{De novo transcriptome assembly}

To obtain a better assembly result, two assembly methods (single k-mer (SK) method and multiple kmer (MK) method) were used for the de novo assembly of these sequencing data. We first performed a test assembly using Illumina reads derived from the SC sample rep1 library with a series of k-mers (28-56) using ABySS [101]. To select an optimal kmer parameter, we compared the summary statistics, including N50s, total contig number, and the total assembly size generated by each k-mer (Additional file 13). After careful consideration, $\mathrm{k}-\mathrm{mer}=41$ was 
chosen for accuracy and the length of the assembled transcripts. Using these identified parameters, a total of 31,591,337,787 nt reads generated from all eight libraries ((dehydration, salt, cold and standard) $\times($ two replicates)) were de novo assembled into contigs. Additionally, Trinity [102] has been shown to be the best SK assembler for transcriptome assembly [103]. Trinity was implemented with default parameters on our 8 library datasets. The results of the MK and SK were combined using the CAP3 programme with default parameters [104]. Finally, the redundant sequences were collapsed using the CD-HIT-EST algorithm [105], producing a total of 98,515 sequences. These sequences span 84,416,200 nt, with an average length of $857 \mathrm{nt}$. The assembly sequences were listed at (http://bioinformatics.cau.edu.cn/falcata/ sequences/all.transcripts).

\section{Putative function, GO, and KEGG orthology annotations}

The assembled reference sequences were aligned to NCBI nr database using BLASTx [106] with a threshold of e-value $\leq 1 \mathrm{e}^{-6}$, and the best three hits were chosen for putative function annotation. KAAS (KEGG Automatic Annotation Server) was used to identify biochemical pathways and to calculate the statistical significance of each pathway [107]. The GO annotations were obtained from scanning the transcriptome by using InterProScan [108].

\section{Differentially expressed transcripts}

The sequencing reads of the four samples were mapped to the M. falcata transcriptome by SOAPaligner [109], with a maximum of three mismatches. Gene expression levels were calculated by RPKM. The expression difference was identified by DEGseq [110], in which Fisher's exact test and the likelihood ratio were proposed to identify differentially expressed genes, and the P- and Qvalues for each gene were calculated. Differentially expressed genes identified by DESeq were required to have a 2-fold change and $\mathrm{P} \leq 0.05$.

\section{qRT-PCR}

We first selected six expressed and relatively stable genes displayed in the RNA-Seq data as internal control candidates. Two reference genes (ID: Mf94657 and Mf85797) were determined by geNorm [111] for qRTPCR analysis. After the total RNA was extracted, reverse transcription was performed using M-MLV Reverse Transcriptase (Promega). The quantitative real-time PCR analysis was conducted using a CFX-96 Real-Time System (Bio-Rad) and SYBR Premix Ex Taq (TaKaRa). All of the specific primers used in this work are listed in Additional file 14.

\section{Determine ABA content}

ABA content was measured as previously described [112]. For cold stress, we transferred the plantlets (4-week-old) to $0{ }^{\circ} \mathrm{C}$ (freezing chamber RuMED4001) for $0 \mathrm{~h}, 2 \mathrm{~h}, 4 \mathrm{~h}$, $6 \mathrm{~h}$ under dim light (0.7-0.8 $\mu \mathrm{mol} \mathrm{sec}-1 \mathrm{~m}-2)$. After cold stress, a total of $20 \mathrm{mg}$ of homogenized M. falcata (PI 502449) and M. truncatula (A17) leaves were soaked in $1 \mathrm{ml}$ of ABA extraction buffer $(10 \mathrm{mM} \mathrm{HCl}$ and $1 \%$ polyvinylpolypyrrolidone in methanol) and shaked at $4{ }^{\circ} \mathrm{C}$ for $16 \mathrm{~h}$. After neutralization with $15 \mu \mathrm{l}$ of $1 \mathrm{M} \mathrm{NaOH}$, the supernatant was dried and resuspended in TBS. The ABA content was quantified using a Phytodetek ABA Test Kit (Agdia, USA). These experiments were repeated three times with similar results.

\section{Auxin treatment experiment}

Plants grown for the auxin treatment experiment were germinated as described above, except that the plantlets were transferred to large Petri pots containing Fahraeus medium [113] vertically and inoculated with Sinorhizobium meliloti strain 1021 in Bergensen's modified medium adjusted to an optical density at $600 \mathrm{~nm}$ $\left[\mathrm{OD}_{600}\right]=0.1$. There were four plantlets per pot. Each pot was two-thirds covered with black paper on the outside. These pots were placed in a growth chamber at $24{ }^{\circ} \mathrm{C}$ under long days ( $16 \mathrm{~h}$ light, $8 \mathrm{~h}$ dark) for $72 \mathrm{~h}$, and the pots were then divided into three sets. (a) Plantlets were supplemented with IAA to a final concentration of $10^{-8} \mathrm{M}$ and grown at $4{ }^{\circ} \mathrm{C}$ under long days for 10 days before being transferred to $24{ }^{\circ} \mathrm{C}$. (b) Plantlets were supplemented with IAA to a final concentration of $10^{-8} \mathrm{M}$ and maintained at $24{ }^{\circ} \mathrm{C}$ under long days. (c) Plantlets were supplied with an equal amount of distilled water and maintained at $24{ }^{\circ} \mathrm{C}$ under long days. All of these plants were collected after 21 days for root measurements and RNA extraction.

\section{Additional files}

Additional file 1: Figure showing effect of cold, drought and salt stresses on M. truncatula 108-R, M. truncatula A17 and M.falcata PI502449. A, Relative raw weights (\%) of root system and aerial part of three Medicago genotypes under different cold stress conditions. B,

Relative raw weights (\%) of root system and aerial part of three Medicago genotypes under different drought stress conditions. C, Relative content of solube carbohydrates of three Medicago genotypes under different salt stress conditions. D, Mortality of three Medicago genotypes under different cold stress conditions. (Student's $t$-test, ${ }^{* *} P<0.001,{ }^{*} P<0.01$ ) (TIFF 13969 kb)

Additional file 2: Figure showing electrolyte leakage of the DS, SS, and CS samples into leaf tissue. Plants were germinated and treated as described in Methods. A, Electrolyte leakage in leaf tissue under cold stress. B, Electrolyte leakage in leaf tissue under dehydration stress. C, Electrolyte leakage in leaf tissue under high salinity stress. (Student's $t$-test, $\left.{ }^{*} P<0.001,{ }^{*} P<0.01\right)$ (TIFF $\left.13168 \mathrm{~kb}\right)$

Additional file 3: Table listing statistics of raw sequencing reads. (XLSX $9 \mathrm{~kb}$ ) 


\section{Additional file 4: Table listing summary of de novo assembly} results. (XLSX $8 \mathrm{~kb})$

Additional file :5 Table listing housekeeping genes. These transcripts were identified as the most stably expressed across all conditions. (XLSX $102 \mathrm{~kb}$ )

Additional file 6: Table listing differentially expressed transcripts potentially regulated by miRNAs. (XLSX $91 \mathrm{~kb}$ )

Additional file 7: Table listing transcripts differentially expressed between abiotic stress and standard. (XLSX $1117 \mathrm{~kb}$ )

Additional file 8: Figure showing heat map of expression profiles of transcription factor. Expression, represented by Z scores, is shown for transcripts differentially expressed due to three abiotic stresses. Red indicates high expression, yellow indicates intermediate expression, and green indicates low expression. Transcripts have been grouped by TF family. (TIFF $21063 \mathrm{~kb}$ )

Additional file 9: Showing effect of cold stress on $A B A$ content in M. truncatula A17 and M.falcata PI502449. A, ABA content in M. truncatula A17. B, ABA content in M. falcata PI502449. (Student's t-test, $\left.{ }^{*} P<0.001,{ }^{*} P<0.01\right)($ TIFF $13100 \mathrm{~kb}$ )

Additional file 10: Table listing differential expression genes involved in phytohormone metabolism and signal transduction. (XLSX $11 \mathrm{~kb}$ )

Additional file 11: Table listing differential expression genes involved in nod factor signaling pathways during early symbiotic nodulation. (XLSX $9 \mathrm{~kb})$

Additional file 12: Figure showing similarity and coverage of $M$. falcata transcripts to $M$. truncatula genes. A, Histogram showing the frequency vs. percent similarity (positive amino acid identity) of $\mathrm{M}$. falcata contigs to a M. truncatula peptide. B, Frequency vs. percent coverage (longest positive hit/peptide length) of $\mathrm{M}$. falcata contigs to a $\mathrm{M}$. truncatula peptide. (note: most assembled M. falcata transcripts have a high coverage, which significantly skews the histogram to the right) $C$, Smoothed colour density representation of the percent similarity ( $x$-axis) of each $M$. falcata transcript plotted against the percent coverage of the M. truncatula protein similarity (y-axis). Plot produced using the 'smoothScatter' function in R, which produces a smoothed density representation of the scatter plot using a kernel density estimate $(\mathrm{nbin}=100)$. Darker colour indicates a higher density of transcripts in a given position. (TIFF $2408 \mathrm{~kb}$ )

Additional file 13: Figure showing optimisation of the de novo assembly. Comparison of the total assembly size (y-axis, left) and the N50 (y-axis, right) using a variety of $k$-mers (x-axis). (TIFF $3922 \mathrm{~kb}$ )

Additional file 14: Table listing primer sequences used for Real Time PCR. (XLSX $13 \mathrm{~kb})$

\section{Competing interests}

The authors declare that they have no competing interests.

\section{Authors' contributions}

$Z M, W X, D L, L Z$ and ZD performed the analysis. XH performed the qRT-PCR experiments. $X H, J L, R Z$ and $Z T$ performed the physiology experiments. MS and WL performed the sequencing experiments. ZM wrote the manuscript. JD and ZS helped to revise the manuscript. TW and SH led the study. All authors read and approved the final manuscript.

\section{Acknowledgements}

This work was supported by grants from the National Basic Research Program of China (973 Program, 2012CB215301) and the Hi-Tech Research and Development (863, 2011AA100209) Program. We thank Dr. Jean Marie Prosperi and Magalie Delalande (BRC for Medicago truncatula, UMR 1097, INRA, Montpellier, France) for providing seeds of Medicago truncatula A17 and R108. We thank the US National Plant Germplasm System (NPGS) in US Department of Agriculture (USDA) for providing Medicago falcata (PI502449) seeds.

\section{Author details}

'State Key Laboratory of Agrobiotechnology, College of Biological Sciences, China Agricultural University, Beijing 100193, China. ${ }^{2}$ CAS Key Laboratory of
Genome Sciences and Information, Beijing Institute of Genomics, Chinese Academy of Sciences, Beijing 100029, China. ${ }^{3}$ State Key Laboratory of Plant Physiology and Biochemistry, College of Biological Sciences, China Agricultural University, Beijing 100193, China. ${ }^{4}$ Present address: Department of Agronomy, Purdue University, West Lafayette, IN, USA. ${ }^{5}$ Present address: Department of Genetics, Center for Genome Sciences and Systems Biology, Washington University School of Medicine, St. Louis, MO, USA.

Received: 4 April 2015 Accepted: 7 October 2015

Published online: 19 October 2015

\section{References}

1. Mahajan S, Tuteja N. Cold, salinity and drought stresses: an overview. Arch Biochem Biophys. 2005;444(2):139-58.

2. Naya L, Ladrera R, Ramos J, Gonzalez EM, Arrese-lgor C, Minchin FR, et al, The response of carbon metabolism and antioxidant defenses of alfalfa nodules to drought stress and to the subsequent recovery of plants. Plant Physiol. 2007;144(2):1104-14.

3. Veatch ME, Smith SE, Vandemark G. Shoot Biomass Production among Accessions of Exposed to NaCl. Crop Sci. 2004:44(3):1008-13.

4. Li D, Zhang Y, Hu X, Shen X, Ma L, Su Z, et al. Transcriptional profiling of Medicago truncatula under salt stress identified a novel CBF transcription factor MtCBF4 that plays an important role in abiotic stress responses. BMC Plant Biol. 2011;11:109.

5. Song S, Chen Y, Zhao M, Zhang W-H. A novel Medicago truncatula HD-Zip gene, MtHB2, is involved in abiotic stress responses. Environ Exp Bot. 2012;80:1-9.

6. Obata T, Fernie AR. The use of metabolomics to dissect plant responses to abiotic stresses. Cell Mol Life Sci. 2012;69(19):3225-43.

7. Ingram J, Bartels D. The Molecular Basis of Dehydration Tolerance in Plants Annu Rev Plant Physiol Plant Mol Biol. 1996;47:377-403.

8. Thomashow MF. PLANT COLD ACCLIMATION: Freezing Tolerance Genes and Regulatory Mechanisms. Annu Rev Plant Physiol Plant Mol Biol. 1999:50:571-99.

9. Wang W, Vinocur B, Altman A. Plant responses to drought, salinity and extreme temperatures: towards genetic engineering for stress tolerance. Planta. 2003:218(1):1-14.

10. Kohli A, Sreenivasulu N, Lakshmanan P, Kumar PP. The phytohormone crosstalk paradigm takes center stage in understanding how plants respond to abiotic stresses. Plant Cell Rep. 2013;32(7):945-57.

11. Singh R, Jwa NS. The rice MAPKK-MAPK interactome: the biological significance of MAPK components in hormone signal transduction. Plant Cell Rep. 2013;32(6):923-31.

12. Cutler SR, Rodriguez PL, Finkelstein RR, Abrams SR. Abscisic acid: emergence of a core signaling network. Annu Rev Plant Biol. 2010;61:651-79.

13. Hirayama T, Shinozaki K. Research on plant abiotic stress responses in the post-genome era: past, present and future. Plant J. 2010;61(6):1041-52.

14. Raghavendra AS, Gonugunta VK, Christmann A, Grill E. ABA perception and signalling. Trends Plant Sci. 2010;15(7):395-401.

15. Sreenivasulu N, Harshavardhan VT, Govind G, Seiler C, Kohli A. Contrapunta role of ABA: does it mediate stress tolerance or plant growth retardation under long-term drought stress? Gene. 2012:506(2):265-73.

16. Sreenivasulu N, Sopory SK, Kavi Kishor PB. Deciphering the regulatory mechanisms of abiotic stress tolerance in plants by genomic approaches. Gene. 2007;388(1-2):1-13.

17. Peleg Z, Blumwald E. Hormone balance and abiotic stress tolerance in crop plants. Curr Opin Plant Biol. 2011;14(3):290-5.

18. Santino A, Taurino M, De Domenico S, Bonsegna S, Poltronieri P, Pastor V, et al. Jasmonate signaling in plant development and defense response to multiple (a)biotic stresses. Plant Cell Rep. 2013;32(7):1085-98.

19. Santner A, Estelle M. Recent advances and emerging trends in plant hormone signalling. Nature. 2009;459(7250):1071-8.

20. Wolters $H$, Jurgens $G$. Survival of the flexible: hormonal growth control and adaptation in plant development. Nat Rev Genet. 2009;10(5):305-17.

21. Kang $Y$, Han $Y$, Torres-Jerez I, Wang $M$, Tang $Y$, Monteros $M$, et al. System responses to long-term drought and re-watering of two contrasting alfalfa varieties. Plant J. 2011;68(5):871-89.

22. Zhang LL, Zhao MG, Tian QY, Zhang WH. Comparative studies on tolerance of Medicago truncatula and Medicago falcata to freezing. Planta. 2011;234(3):445-57. 
23. Clark G, Malte M. Fodder and pasture plants. Canada: Department of Agriculture; 1913.

24. Tan J, Wang C, Xiang B, Han R, Guo Z. Hydrogen peroxide and nitric oxide mediated cold- and dehydration-induced myo-inositol phosphate synthase that confers multiple resistances to abiotic stresses. Plant Cell Environ. 2013;36(2):288-99.

25. Tan J, Zhuo C, Guo Z. Nitric oxide mediates cold- and dehydration-induced expression of a novel MfHyPRP that confers tolerance to abiotic stress. Physiol Plant. 2013;149(3):310-20.

26. Zhuo C, Wang T, Lu S, Zhao Y, Li X, Guo Z. A cold responsive galactinol synthase gene from Medicago falcata (MfGolS1) is induced by myo-inositol and confers multiple tolerances to abiotic stresses. Physiol Plant. 2013;149(1):67-78.

27. Guo Z, Tan J, Zhuo C, Wang C, Xiang B, Wang Z. Abscisic acid, H2O2 and nitric oxide interactions mediated cold-induced S-adenosylmethionine synthetase in Medicago sativa subsp. falcata that confers cold tolerance through up-regulating polyamine oxidation. Plant Biotechnol J. 2014;12(5):601-12

28. Sambe MA, He X, Tu Q, Guo Z. A cold-induced myo-inositol transporter-like gene confers tolerance to multiple abiotic stresses in transgenic tobacco plants. Physiol Plant. 2015;153(3):355-64.

29. Uemura M, Tominaga $Y$, Nakagawara C, Shigematsu S, Minami A, Kawamura $Y$. Responses of the plasma membrane to low temperatures. Physiol Plant. 2006;126(1):81-9.

30. He X, Sambe MA, Zhuo C, Tu Q, Guo Z. A temperature induced lipocalin gene from Medicago falcata (MfTIL1) confers tolerance to cold and oxidative stress. Plant Mol Biol. 2015;87(6):645-54.

31. Graham PH, Vance CP. Legumes: importance and constraints to greater use. Plant Physiol. 2003;131(3):872-7.

32. Becker A, Berges H, Krol E, Bruand C, Ruberg S, Capela D, et al. Global changes in gene expression in Sinorhizobium meliloti 1021 under microoxic and symbiotic conditions. Mol Plant Microbe Interact. 2004;17(3):292-303.

33. Benedito VA, Torres-Jerez I, Murray JD, Andriankaja A, Allen S, Kakar K, et al. A gene expression atlas of the model legume Medicago truncatula. Plant $J$. 2008;55(3):504-13.

34. Capela D, Filipe C, Bobik C, Batut J, Bruand C. Sinorhizobium meliloti differentiation during symbiosis with alfalfa: a transcriptomic dissection. Mol Plant Microbe Interact. 2006;19(4):363-72.

35. El Yahyaoui F, Kuster H, Ben Amor B, Hohnjec N, Puhler A, Becker A, et al. Expression profiling in Medicago truncatula identifies more than 750 genes differentially expressed during nodulation, including many potential regulators of the symbiotic program. Plant Physiol. 2004;136(2):3159-76.

36. Maunoury N, Redondo-Nieto M, Bourcy M, Van de Velde W, Alunni B, Laporte $P$, et al. Differentiation of symbiotic cells and endosymbionts in Medicago truncatula nodulation are coupled to two transcriptome-switches. Plos One. 2010;5(3), e9519.

37. Moreau S, Verdenaud M, Ott T, Letort S, de Billy F, Niebel A, et al. Transcription reprogramming during root nodule development in Medicago truncatula. PloS One. 2011;6(1), e16463.

38. Limpens E, Moling S, Hooiveld G, Pereira PA, Bisseling T, Becker JD, et al. Cell- and tissue-specific transcriptome analyses of Medicago truncatula root nodules. Plos One. 2013;8(5), e64377.

39. Boscari A, Del Giudice J, Ferrarini A, Venturini L, Zaffini AL, Delledonne M, et al. Expression dynamics of the Medicago truncatula transcriptome during the symbiotic interaction with Sinorhizobium meliloti: which role for nitric oxide? Plant Physiol. 2013;161(1):425-39.

40. Roux B, Rodde N, Jardinaud MF, Timmers T, Sauviac L, Cottret L, et al. An integrated analysis of plant and bacterial gene expression in symbiotic root nodules using laser-capture microdissection coupled to RNA sequencing. Plant J. 2014;77(6):817-37.

41. Oldroyd GE, Downie JA. Coordinating nodule morphogenesis with rhizobial infection in legumes. Annu Rev Plant Biol. 2008;59:519-46.

42. Mitra RM, Long SR. Plant and bacterial symbiotic mutants define three transcriptionally distinct stages in the development of the Medicago truncatula/Sinorhizobium meliloti symbiosis. Plant Physiol. 2004;134(2):595-604

43. Schuster SC. Next-generation sequencing transforms today's biology Nat Methods. 2008:5(1):16-8.

44. Denoeud F, Aury JM, Da Silva C, Noel B, Rogier O, Delledonne M, et al. Annotating genomes with massive-scale RNA sequencing. Genome Biol. 2008;9(12):R175
45. Wang Z, Gerstein M, Snyder M. RNA-Seq: a revolutionary tool for transcriptomics. Nat Rev Genet. 2009;10(1):57-63.

46. Leyva-Gonzalez MA, Ibarra-Laclette E, Cruz-Ramirez A, Herrera-Estrella L. Functional and transcriptome analysis reveals an acclimatization strategy for abiotic stress tolerance mediated by Arabidopsis NF-YA family members. Plos One. 2012;7(10), e48138.

47. Zhu YN, Shi DQ, Ruan MB, Zhang LL, Meng ZH, Liu J, et al. Transcriptome analysis reveals crosstalk of responsive genes to multiple abiotic stresses in cotton (Gossypium hirsutum L.). PloS One. 2013;8(11):e80218.

48. Severin AJ, Woody JL, Bolon Y-T, Joseph B, Diers BW, Farmer AD, et al. RNA-Seq Atlas of Glycine max: a guide to the soybean transcriptome. BMC Plant Biol. 2010;10(1):160.

49. Cheung F, Haas BJ, Goldberg SM, May GD, Xiao Y, Town CD. Sequencing Medicago truncatula expressed sequenced tags using 454 Life Sciences technology. BMC Genomics. 2006;7(1):272.

50. Cabeza RA, Liese R, Lingner A, von Stieglitz I, Neumann J, Salinas-Riester G, et al. RNA-seq transcriptome profiling reveals that Medicago truncatula nodules acclimate $\mathrm{N} 2$ fixation before emerging $P$ deficiency reaches the nodules. J Exp Bot. 2014;65(20):6035-48.

51. De Michele R, Formentin E, Todesco M, Toppo S, Carimi F, Zottini M, et al. Transcriptome analysis of Medicago truncatula leaf senescence: similarities and differences in metabolic and transcriptional regulations as compared with Arabidopsis, nodule senescence and nitric oxide signalling. New Phytol. 2009;181(3):563-75.

52. Yang SS, Tu ZJ, Cheung F, Xu WW, Lamb JF, Jung HJ, et al. Using RNA-Seq for gene identification, polymorphism detection and transcript profiling in two alfalfa genotypes with divergent cell wall composition in stems. BMC Genomics. 2011;12:199.

53. Li X, Acharya A, Farmer AD, Crow JA, Bharti AK, Kramer RS, et al. Prevalence of single nucleotide polymorphism among 27 diverse alfalfa genotypes as assessed by transcriptome sequencing. BMC Genomics. 2012;13(1):568.

54. Aziz N, Paiva NL, May GD, Dixon RA. Transcriptome analysis of alfalfa glandular trichomes. Planta. 2005;221(1):28-38.

55. Han Y, Kang Y, Torres-Jerez I, Cheung F, Town CD, Zhao PX, et al. Genomewide SNP discovery in tetraploid alfalfa using 454 sequencing and high resolution melting analysis. BMC Genomics. 2011;12(1):350.

56. Kaur S, Cogan NO, Pembleton LW, Shinozuka M, Savin KW, Materne M, et al. Transcriptome sequencing of lentil based on second-generation technology permits large-scale unigene assembly and SSR marker discovery. BMC Genomics. 2011;12:265.

57. Franssen SU, Shrestha RP, Brautigam A, Bornberg-Bauer E, Weber AP. Comprehensive transcriptome analysis of the highly complex Pisum sativum genome using next generation sequencing. BMC Genomics. 2011;12:227

58. Dubey A, Farmer A, Schlueter J, Cannon SB, Abernathy B, Tuteja R, et al. Defining the transcriptome assembly and its use for genome dynamics and transcriptome profiling studies in pigeonpea (Cajanus cajan L.). DNA Res 2011;18(3):153-64.

59. Blanca J, Canizares J, Roig C, Ziarsolo P, Nuez F, Pico B. Transcriptome characterization and high throughput SSRs and SNPs discovery in Cucurbita pepo (Cucurbitaceae). BMC Genomics. 2011;12:104.

60. Garg R, Patel RK, Tyagi AK, Jain M. De novo assembly of chickpea transcriptome using short reads for gene discovery and marker identification. DNA Res. 2011;18(1):53-63.

61. Mizrachi E, Hefer CA, Ranik M, Joubert F, Myburg AA. De novo assembled expressed gene catalog of a fast-growing Eucalyptus tree produced by Illumina mRNA-Seq. BMC Genomics. 2010;11:681.

62. Wang Z, Fang B, Chen J, Zhang X, Luo Z, Huang L, et al. De novo assembly and characterization of root transcriptome using Illumina paired-end sequencing and development of cSSR markers in sweet potato (Ipomoea batatas). BMC Genomics. 2010;11:726.

63. O'Rourke JA, Yang SS, Miller SS, Bucciarelli B, Liu J, Rydeen A, et al. An RNA-Seq transcriptome analysis of orthophosphate-deficient white lupin reveals novel insights into phosphorus acclimation in plants. Plant Physiol. 2013;161(2):705-24.

64. Limami AM, Ricoult C, Planchet E, González EM, Ladrera R, Larrainzar E, et al. Response of Medicago truncatula to abiotic stress. In: Mathesius $U$, Journet EP, Summer LW, editors. The Medicago truncatula handbook. 2007. ISBN 0-97543036169. http://www.noble.org/MedicagoHandbook.

65. Langfelder $P$, Horvath S. WGCNA: an R package for weighted correlation network analysis. BMC Bioinformatics. 2008;9:559. 
66. Burke GR, Strand MR. Deep sequencing identifies viral and wasp genes with potential roles in replication of Microplitis demolitor Bracovirus. J Virol. 2012;86(6):3293-306

67. Zhao J, Ohsumi TK, Kung JT, Ogawa Y, Grau DJ, Sarma K, et al. Genomewide identification of polycomb-associated RNAs by RIP-seq. Mol Cell. 2010;40(6):939-53

68. Czechowski T, Stitt M, Altmann T, Udvardi MK, Scheible WR. Genome-wide identification and testing of superior reference genes for transcript normalization in Arabidopsis. Plant Physiol. 2005;139(1):5-17.

69. Sunkar R. MicroRNAs with macro-effects on plant stress responses. Semin Cell Dev Biol. 2010;21(8):805-11.

70. Sunkar R, Zhu JK. Novel and stress-regulated microRNAs and other small RNAs from Arabidopsis. Plant Cell. 2004;16(8):2001-19.

71. Dai $X B$, Zhao PX. psRNATarget: a plant small RNA target analysis server. Nucleic Acids Res. 2011;39:W155-9.

72. Khraiwesh B, Pugalenthi G, Fedoroff NV. Identification and analysis of red sea mangrove (Avicennia marina) microRNAs by high-throughput sequencing and their association with stress responses. PloS One. 2013;8(4), e60774.

73. Pandey B, Gupta OP, Pandey DM, Sharma I, Sharma P. Identification of new stress-induced microRNA and their targets in wheat using computational approach. Plant Signal Behav. 2013;8(5):e23932.

74. Zhang S, Yue Y, Sheng L, Wu Y, Fan G, Li A, et al. PASmiR: a literaturecurated database for miRNA molecular regulation in plant response to abiotic stress. BMC Plant Biol. 2013;13:33.

75. de Lima JC, Loss-Morais G, Margis R. MicroRNAs play critical roles during plant development and in response to abiotic stresses. Genet Mol Biol. 2012;35(4 (suppl)):1069-77.

76. Daszkowska-Golec A, Chorazy E, Maluszynski M, Szarejko I. Towards the Identification of New Genes Involved in ABA-Dependent Abiotic Stresses Using Arabidopsis Suppressor Mutants of abh1 Hypersensitivity to ABA during Seed Germination. Int J Mol Sci. 2013;14(7):13403-32.

77. Lange T, Kappler J, Fischer A, Frisse A, Padeffke T, Schmidtke S, et al. Gibberellin biosynthesis in developing pumpkin seedlings. Plant Physiol. 2005;139(1):213-23.

78. Kende H. Enzymes of ethylene biosynthesis. Plant Physiol. 1989;91(1):1-4

79. Wasternack $C_{1}$ Hause B. Jasmonates: biosynthesis, perception, signal transduction and action in plant stress response, growth and development. An update to the 2007 review in Annals of Botany. Ann Bot. 2013;111(6):1021-58.

80. Cheng MC, Liao PM, Kuo WW, Lin TP. The Arabidopsis ETHYLENE RESPONSE FACTOR1 Regulates Abiotic Stress-Responsive Gene Expression by Binding to Different cis-Acting Elements in Response to Different Stress Signals. Plant Physiol. 2013:162(3):1566-82

81. Jain M, Khurana JP. Transcript profiling reveals diverse roles of auxinresponsive genes during reproductive development and abiotic stress in rice. FEBS J. 2009;276(11):3148-62

82. Broghammer A, Krusell L, Blaise M, Sauer J, Sullivan JT, Maolanon N, et al. Legume receptors perceive the rhizobial lipochitin oligosaccharide signal molecules by direct binding. Proc Natl Acad Sci U S A. 2012;109(34):13859-64

83. Svistoonoff S, Sy MO, Diagne N, Barker DG, Bogusz D, Franche C. Infectionspecific activation of the Medicago truncatula Enod11 early nodulin gene promoter during actinorhizal root nodulation. Mol Plant Microbe Interact. 2010;23(6):740-7

84. Ariel F, Brault-Hernandez M, Laffont C, Huault E, Brault M, Plet J, et al. Two direct targets of cytokinin signaling regulate symbiotic nodulation in Medicago truncatula. Plant Cell. 2012;24(9):3838-52.

85. Wojciechowski MF, Lavin M, Sanderson MJ. A phylogeny of legumes (Leguminosae) based on analysis of the plastid matK gene resolves many well-supported subclades within the family. Am J Bot. 2004;91(11):1846-62

86. Vashisht AA, Pradhan A, Tuteja R, Tuteja N. Cold- and salinity stress-induced bipolar pea DNA helicase 47 is involved in protein synthesis and stimulated by phosphorylation with protein kinase C. Plant J. 2005;44(1):76-87.

87. Owttrim GW. RNA helicases and abiotic stress. Nucleic Acids Res. 2006;34(11):3220-30.

88. Amor $Y$, Babiychuk E, Inze D, Levine A. The involvement of poly(ADP-ribose) polymerase in the oxidative stress responses in plants. FEBS Lett. 1998:440(1-2):1-7.

89. De Block M, Verduyn C, De Brouwer D, Cornelissen M. Poly(ADP-ribose) polymerase in plants affects energy homeostasis, cell death and stress tolerance. Plant J. 2005;41(1):95-106.

90. Hayashi H, Alia, Mustardy L, Deshnium P, Ida M, Murata N. Transformation of Arabidopsis thaliana with the codA gene for choline oxidase; accumulation of glycinebetaine and enhanced tolerance to salt and cold stress. Plant J. 1997:12(1):133-42

91. Alia, H H, Sakamoto A, Murata N. Enhancement of the tolerance of Arabidopsis to high temperatures by genetic engineering of the synthesis of glycinebetaine. Plant J. 1998;16(2):155-61.

92. Takasaki H, Maruyama K, Kidokoro S, Ito Y, Fujita Y, Shinozaki K, et al. The abiotic stress-responsive NAC-type transcription factor OsNAC5 regulates stress-inducible genes and stress tolerance in rice. Mol Genet Genomics. 2010;284(3):173-83.

93. Nuruzzaman M, Manimekalai R, Sharoni AM, Satoh K, Kondoh H, Ooka H, et al. Genome-wide analysis of NAC transcription factor family in rice. Gene. 2010;465(1-2):30-44.

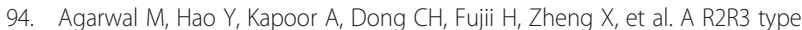
MYB transcription factor is involved in the cold regulation of CBF genes and in acquired freezing tolerance. J Biol Chem. 2006;281(49):37636-45.

95. Taji T, Seki M, Satou M, Sakurai T, Kobayashi M, Ishiyama K, et al. Comparative genomics in salt tolerance between Arabidopsis and aRabidopsis-related halophyte salt cress using Arabidopsis microarray. Plant Physiol. 2004;135(3):1697-709.

96. Gonzalez-Guzman M, Pizzio GA, Antoni R, Vera-Sirera F, Merilo E, Bassel GW et al. Arabidopsis PYR/PYL/RCAR receptors play a major role in quantitative regulation of stomatal aperture and transcriptional response to abscisic acid. Plant Cell. 2012;24(6):2483-96.

97. Pennycooke JC, Cheng H, Stockinger EJ. Comparative genomic sequence and expression analyses of Medicago truncatula and alfalfa subspecies falcata COLD-ACCLIMATION-SPECIFIC genes. Plant Physiol. 2008;146(3):1242-54.

98. Brummer EC, Cazcarro PM, Luth D. Ploidy determination of alfalfa germplasm accessions using flow cytometry. Crop Sci. 1999;39(4):1202-7.

99. Yamaguchi-Shinozaki K, Shinozaki K. A novel cis-acting element in an Arabidopsis gene is involved in responsiveness to drought, lowtemperature, or high-salt stress. Plant Cell. 1994;6(2):251-64.

100. Lu T, Lu G, Fan D, Zhu C, Li W, Zhao Q, et al. Function annotation of the rice transcriptome at single-nucleotide resolution by RNA-seq. Genome Res. 2010;20(9):1238-49.

101. Birol I, Jackman SD, Nielsen CB, Qian JQ, Varhol R, Stazyk G, et al. De novo transcriptome assembly with ABySS. Bioinformatics. 2009;25(21):2872-7.

102. Grabherr MG, Haas BJ, Yassour M, Levin JZ, Thompson DA, Amit I, et al. Full-length transcriptome assembly from RNA-Seq data without a reference genome. Nature Biotechnol. 2011;29(7):644-52.

103. Zhao QY, Wang Y, Kong YM, Luo D, Li X, Hao P. Optimizing de novo transcriptome assembly from short-read RNA-Seq data: a comparative study. BMC Bioinformatics. 2011:12 Suppl 14:S2.

104. Huang X, Madan A. CAP3: A DNA sequence assembly program. Genome Res. 1999;9(9):868-77.

105. Li W, Godzik A. Cd-hit: a fast program for clustering and comparing large sets of protein or nucleotide sequences. Bioinformatics. 2006;22(13):1658-9.

106. Altschul SF, Gish W, Miller W, Myers EW, Lipman DJ. Basic local alignment search tool. J Mol Biol. 1990;215(3):403-10.

107. Moriya Y, Itoh M, Okuda S, Yoshizawa AC, Kanehisa M. KAAS: an automatic genome annotation and pathway reconstruction server. Nucleic Acids Res. 2007;35(Web Server issue):W182-185.

108. Zdobnov EM, Apweiler R. InterProScan-an integration platform for the signature-recognition methods in InterPro. Bioinformatics. 2001;17(9):847-8.

109. Li R, Yu C, Li Y, Lam TW, Yiu SM, Kristiansen K, et al. SOAP2: an improved ultrafast tool for short read alignment. Bioinformatics. 2009:25(15):1966-7.

110. Wang L, Feng Z, Wang X, Zhang X. DEGseq: an R package for identifying differentially expressed genes from RNA-seq data. Bioinformatics. 2010;26(1):136-8

111. Vandesompele J, De Preter K, Pattyn F, Poppe B, Van Roy N, De Paepe A et al. Accurate normalization of real-time quantitative RT-PCR data by geometric averaging of multiple internal control genes. Genome Biol. 2002;3(7):RESEARCH0034

112. Estévez JM, Cantero A, Reindl A, Reichler S, León P. 1-Deoxy-D-xylulose-5phosphate synthase, a limiting enzyme for plastidic isoprenoid biosynthesis in plants. J Biol Chem. 2001;276(25):22901-9.

113. Vincent JM. A manual for the practical study of the root-nodule bacteria. 1970

114. Schmittgen TD, Livak KJ. Analyzing real-time PCR data by the comparative CT method. Nat Protoc. 2008:3(6):1101-8. 